USAD, Güz 2021; (15): 195-234

E-ISSN: 2548-0154

\title{
BARTIN TEREKE KAYITLARINA GÖRE 19. YÜZYILDA KADINLARDA GIYYIM KUŞAM ${ }^{1}$
}

\section{WOMEN'S CLOTHING IN THE 19TH CENTURY ACCORDING TO BARTIN TEREKE RECORDS}

Mine DILEK*

$\ddot{O} z$

Şer'iye sicilleri, Osmanl şehirlerinde kadılar tarafindan tutulan ve mahkeme tutanakları olarak ifade edilen defterlerdir. Bu defterlerde tereke, diğer adıyla muhallefat kayıtlar ölen kişilerin eşyalarının kadının gözetiminde tek tek fiyat ve adediyle birlikte kaleme alındiğg kayıtlarda tutulmuştur. Tereke kayıtları, stradan bir Osmanlı ailesinin evinin içini hayal etmemize olanak verecek veriler sağlar. Yöreden yöreye farkllık gösteren bu bilgiler yerel tarih araştırmaları için önemli veri kaynaklarının başında gelir. Kullanılan ev araç ve gereçlerinden tercih giyim kuşam anlayışına kadar farklı bilgilere tereke kayıtlarından ulaşmak mümkündür.

Bu çalışmada Bartın yöresinin 19. yüzyıla ait kadın giyim anlayışı tereke kayıtları üzerinden değerlendirilecektir. 1892-1913 yılların kapsayan 800, 802, 806, 807, 808 ve 810 numaralı Bartın şer'iye sicillerinde yer alan 12 kadın terekesine dayanarak 19. yüzyılın sonlarn ve 20. yüzyllın başlarında Bartın yöresinin kadın kıyafetleri ve giyim kültürüne dair değerlendirmeler yapılmıştır. Osmanl döneminde Müslüman, Rum ve Ermeni unsurların bir arada uyum içinde yaşadığ Bartın'ın kültürel zenginliği, giyim kültüründe de kendini göstermektedir. Şehrin 19. yüzyılda

1 Bu çalışma Bartın Üniversitesi Bilimsel Araştırma Projeleri Koordinasyon Birimi tarafından desteklenen 2020-SOS-A-004 numaralı Geleneksel Bartın Kadın Kıyafetleri isimli projeden türetilmiştir.

*Dr. Öğr. Üyesi, Bartın Üniversitesi Edebiyat Fakültesi Tarih Bölümü Bartın/Türkiye, minedemir@bartin.edu.tr, https://orcid.org/0000-0002-4897-9030

\begin{tabular}{|l||l|l|}
\hline Gönderim Tarihi: 03.11.2021 & Kabul Tarihi: 21.12.2021 \\
\hline
\end{tabular} 


\title{
196 | USAD Mine DILLEK
}

İstanbul ile yoğun ticari bağlantısının bulunması İstanbul giyim kültürünün izlerinin şehre yansımasına olanak vermiştir. Elde edilen bulgular üzerinden şehrin 19. yüzyıldaki sosyal ve ekonomik yapısına dair çıkarımlar yapılmıştır.

\section{Anahtar Kelimeler}

Şer'iye sicilleri, Bartın, kadın, giyim kuşam, 19. Yüzyıl

\begin{abstract}
Court registers are the books kept by the kadi in Ottoman cities and referred to as court minutes. In these notebooks, wealth records, also known as muhallefat records, were kept in the records where the belongings of the deceased were written one by one, together with the price and quantity, under the supervision of the cadilesker. The wealth records provide data that will allow us to imagine the interior of an ordinary Ottoman family's home. This information, which differs from region to region, is one of the most important data sources for local history research. It is possible to reach various information from the wealth records, from the household tools and equipment used to the preferred clothing understanding.
\end{abstract}

In this study, the 19th century women's clothing understanding of the Bartin region will be evaluated through the wealth records. Based on the 12 women's wealth in the Bartm Court Registers numbered 800, 802, 806, 807, 808 and 810 covering the years 1892-1913, evaluations were made about the women's clothing and clothing culture of the Bartm region in the late 19th and early 20th centuries. The cultural richness of Bartm, where Muslims, Greeks and Armenians lived in harmony during the Ottoman period, also shows itself in the clothing culture. The city's intense commercial connection with Istanbul in the 19th century allowed the traces of Istanbul's clothing culture to be reflected in the city. Based on the findings, inferences were made about the social and economic structure of the city in the 19th century.

\section{Keywords}

Court registers, Bartin, woman, clothing, 19th century 


\section{GİRIŞ}

Maddi kültürün bir öğesi olarak giyim, bir milletin milli kültürünü, gelenek ve göreneklerini, yaşam biçimini simgeleyen ve tanıtan unsurlardan biridir. Giyim tarihi incelendiğinde eski devirlerden bu güne kadar giyinme biçimlerinin pek çok aşama kaydettiği görülür. Her milletin kendi yaşama şekli, kültür ve dini inanışına göre bir giyim şekli oluşturduğu dikkati çeker (Dursun vd., 2019, s. 56). Geleneksel giysiler; toplumdaki sosyal ve kültürel yapıyı, ekonomik durumu, beğenileri ve etnik yapılar arasındaki etkileşimi gibi farklı hususa dair bilgi sunarlar. Kullanılan kumaşlar, aksesuarlar ve motifler gibi kıyafeti oluşturan diğer unsurlar o toplumun gelenek ve göreneğini belgeler. Giyim kuşam alışkanlıkları özellikle şehir tarihi çalışmaları için değerlendirilmesi gereken hususlar arasındadır (Faroqhi, 2018).

Osmanlı Devleti'nde giyim kültürü ile ilgili bizlere 1şık tutacak önemli kaynaklardan birisi tereke defterleridir. Kadı (şer'iye) sicilleri içinde yer alan tereke defterleri, bir diğer ifade ile metrûkât ya da muhallefât defterleri, ölen kimselerin geride bıraktıkları malları tespit ile bu malların şeriat esaslarına göre taksimini gösteren kadı defterleridir (İnalcık, 1953, s. 52.) Tereke kayıtları, ölen kişinin en küçük eşyanın dahi kayıt edildiği bu anlamda kişi özelinde gündelik hayatı veya toplumsal ölçekte dönemin sosyo-kültürel yaşamına ışık tutarlar (Barkan, 1996, s. 2; Gündüz, 2019, s. 585). Bu kayıtlara dayanarak Osmanlı Devleti'nin farklı yörelerindeki giyim kültürüne dair bilgi sahibi olmaktayı (Hanliçe, 2011). Bu çalışmada Bartın kadı sicillerden yararlanarak 19. yüzyılda Bartın yöresi geleneksel kadın kıyafetleri ele alınmıştır. Bartın'a ait 1892-1913 yıllarını kapsayan 11 adet şer'iye sicil defteri bulunmaktadır. Çalışmamız kapsamında 800, 802, 806, 807, 808 ve 810 numaralı altı adet Bartın Şer'iye Sicilinde yer alan 12 kadın terekesi incelenerek Bartın kadın giyim kültürüne dair değerlendirmeler yapılmıştır. Değerlendirilen terekelerde kadın giyim kuşamının dökümü çıkarılarak eşyalar, başa takılan giyim parçaları, bedene giyilen giyim parçaları ve giysi tamamlayıcıları başlıkları altında gruplandırılarak ele alınmıştır. Ayrıca terekelerde yer alan eşya türleri sayılarına göre tespit edilmiş ve ayrı tablolar halinde gösterilmiştir. Ele alınan terekeler üzerinden şehrin sosyal ve kültürel hayatına dair çıkarımlar yapabilmek için 12 tereke sahibinin toplam tereke miktarı ve kıyafetlere ayrılan miktarlar tablo halinde verilmiştir.

Osmanlı döneminde Rum, Ermeni ve Müslüman nüfusun bir arada yaşadığı Bartın yöresi sahip olduğu kültürel çeşitliliğin neticesi olarak geleneksel giyim kültürü açısından dikkat çekmektedir. Dokumasında altın veya gümüş telleri olan, 
kendinden desenli, ipekli bir kumaştan yapılan "kolsuz uskufe yelek"in Bartın geleneksel kadın kıyafeti olarak ön plana çıktığı görülmektedir². Yöreye ait kadın giysisi olarak kabul edilen uskufe yeleğin 19. yüzyılda Bartın’a özgü bir giysi çeşidi olduğu iddia edilmektedir (Bartın Halk Kültürü, 1996, s. 1190). Günümüzde uskufe yelek başta olmak üzere geleneksel giyim örnekleri şehirde yer alan müzelerde muhafaza edilmektedir. Bu eserler tarihi değerleri kadar kumaş, model, işleme teknikleri, motif ve desen özellikleriyle geleneksel Türk sanatının eşsiz örnekleri arasindadir.

Osmanlı döneminde farklı unsurların bir arada uyum içinde yaşadığı Bartın'ın kültürel zenginliğinin giyim kültürüne de yansıması beklenir. Bununla beraber 19. yüzyılda İstanbul ile ticari bağlantının yoğun olması İstanbul giyim kültürünün izlerinin şehre taşımıştır. Diğer taraftan değerli madeni iplerle dokunmuş kumaşların şehirde kullanılıyor olması maddi zenginliğin kanıtıdır.

Bartın yöresinde kadınların geleneksel kıyafetleri günlük, özel ve gelinlik giysiler olarak sınıflandırılmakla birlikte giyen kişilerin yaşlarına göre de kıyafetlerinde farklılıklar bulunmaktadır. Genç kızlarda; uskufe veya kutni/kutnu ${ }^{3}$ yelek, ipek göynek/gömlek, şalvar, tombaklı kemer ile tel kırma veya çatkı/çatku yazma ve üstüne değerli mücevherlerden oluşan taçla karakterize edilmiş bir form bulunmaktadır. Kadınlarda ise göynek, şalvar ve zaman zaman da eski desenleri taşıyan yazmadan oluşan bir form kullanırmıştır. Bartın gelin kıyafeti ipekli şalvar, önü düğmeli kollu ipekli ceket üzerine uskufe yelek elmas taç üzerinde başı saran ve dizlere kadar inen kalın ipekli poşudan (duvak) oluşur (Bartın Halk Kültürüu, 1996, s. 1192).

Yörede kullanılan geleneksel kıyafetler daha ziyade şalvar, salta ve iç gömlekleri ile beraber üç parçadan ibarettir. Her üçü de aynı renkte ve aynı

${ }^{2}$ Dokundukları kumaşın ismiyle anılan geleneksel uskufeler, yöreden yöreye çeşitlilik göstererek farklı isimlerle anılmaktadır. Örneğin, Ege bölgesinde yaygın olarak üç etek olarak bilinmektedir Bartın yöresindeki örnekleri; içi pamuk astarlı olup, kol ağızları, yakası dantelli ve önü boydan boya açık kolsuz yelek şeklinde hazırlanmışır. Bartın uskufeleri, yarım ipekli ve tam ipekli kumaştan yapılmış uzun kolsuz yelek biçiminde bir üst giyim olarak tanımlanmaktadır. İçi pamuk astarlı olup, kol ağızları, yakası dantelli ve önü boydan boya açık kolsuz yelek şeklinde hazırlanmıştır. İçlik denilen aynı kumaştan hazırlanmış ceket üzerine giyilir. Bartın'daki uskufe örnekleri daha ziyade Bursa dokumasıdır. Sarı zemin üzerine gül, karanfil, lale ve badem gibi çiçek veya baklava desenlidir. Bartın'ın geleneksel kadın giyiminde önemli bir yere sahip olan uskufeler, gelin kıyafeti olarak kullanılmıştır. Bu giysi türüne Zonguldak ve çevresinde de rastlanılmaktadır (Bartın Halk Kültürü, 1996, s.1191).

${ }^{3}$ Kutnu, bir yüzü ipekli bir yüzü pamuklu eni dar kumaşa verilen isimdir. Önceleri elbiselerde kullanılan bu kumaş türü daha sonra döşemlerde kullanılmıştır. (Koçu, 1996, s.161; Dağlı, 2007, s. 180.) 
kumaştan dikilir ve işlemeleri de aynı tekniktedir. Anadolu'da gerek biçim ve gerek işlemeleri bakımından bölgeden bölgeye çeşitlilik gösteren bu kıyafet çeşidi Bartın'da tek tip olarak karşımıza çıkmaktadır.

Bartın kıyafetlerinde dikkat çeken bir diğer husus bindallının yer almamasıdır. Anadolu'nun köy ve şehirlerinde kadınlar arasında pek fazla yayılmış olduğu sık karşılaşılan örneklerden anlaşılan çoğunlukla bindallı adı verilen entarilere Bartın giyim kültüründe daha nadir rastlanır.

Bartın'ın geleneksel kadın giyiminin en geçerli örneği, uskufe yelek ve içliğinden oluşan beline kemer sabitlenen kıyafet formudur. Sarı zemin üzerine renkli ipliklerle çiçek ve ayrıca simle dokunmuş bir kumaştan yapılmış uzun kadın yeleği, içi astarlı ve pamuklu olarak dikilmiştir. Yeleğin önü ve kollarının etrafı sim, kordon ve sutaşıyla muhtelif şekillerle işlenmiştir. Yeleklerin çevresi kol ağızları siyah şeritli (kaytan), yakaları "harç, divdik, çıkartma" gibi isimlendirilen işlemelerle süslüdür. Yine aynı kumaştan yapılmış ve içlik denilen kısa ve uzun kollu ceketinin de yakası, etek ve kol uçları aynı şekilde işlenmiştir (Bartın Halk Kültürü, 1996, s. 1192; Murat, 2002, s. 88).

\section{Bartın Tereke Kayıtlarına Göre Geleneksel Kadın Giyimi}

İncelediğimiz Bartın sicillerinde yer alan tereke kayıtları, folklorik izlerin tespiti açısından Bartın kadın kıyafetinin detaylarını belirlememize dair bulgular sağlamıştır. Yukarıda belirttiğimiz üzere 1892-1913 yılarını kapsayan sicil defterlerinde 12 adet kadın terekesine ulaşıldı. Tespit edilen terekelerin tamamı Müslüman kadınlara aittir. Yörede gayrimüslim nüfus bulunmasına karşın sicillerde gayrimüslim nüfusa ait terekeler yer almamıştır. Dolayısıyla Müslüman ve gayrimüslim nüfusun tercihleri arasındaki farklılığı tespit etmemize olanak tanımaz. Ancak gelir seviyesi farklı grupların giyim tercihlerine dair çıkarım yapabilmekteyiz. En zengin, en fakir ve ortalama terekesi olan kişiler tespit edilerek giyim tercihlerinin benzer ya da farklı yönler ortaya konulmuştur.

Ele alınan terekelerde 30 farklı grupta kadın giysisi çeşidi bulunmaktadır. Abaniye, bağlak, börk, ceket, çevre, çorap, dizlik, entari, fes, gömlek, hırka, işlik, kafes-i bedeni, kemer kuşak, kundura, kuşak, mendil, nalın, nakışlı paça, pabuç, peştamal, şal, şalvar, uçkur, yağlık, yaşmak örtüsü, yazma, yelek. Giyim eşyaları içerisinde bedene giyilenler eşyalar ağırlıktadır. Başörtüsü çeşitleri, ceket, entari, şalvar terekelerde geniş bir yer tutmaktadır. Giyim parçaları genellikle kullanılan kumaş türüne göre alt bir isimle de tanımlanmıştır. Örneğin kadife, şazen, yünlü, kutni, ipek, canfes gibi kumaş türleri giysi isminin önünde kullanılmıştır. Diğer taraftan giyim kuşamı tamamlayan çeşitli aksesuarlara rastlanmıştır. Aksesuarlar arasında elmaslı çelenk olarak geçen gelin tacı değer bakımından önem 
taşımaktadır. Yöreye özgü giyim kuşam parçalarından biri olarak dikkat çekicidir. İncelemede giyim eşyalarının yanında Bartınlı kadınların sahip oldukları ziynet eşyaları da tespit edilmiştir (Bkz, Tablo 3). Terekelerde yer alan giysiler betimlenirken kullanılmış, eskiyip yıpranmış anlamına gelen müstamel ve köhne sıfatları sıklıkla geçmektedir. Bu kıyafetlerin bazıları eski ve kullanılmış bazıları da yenidir. Bu sebeple aynı kıyafetin değişik fiyatlarla tespit edildiği ortaya çıkmaktadır (Özlü, 2003, s. 107). Aşağıdaki tabloda şer'iye sicillerine göre 19. yüzyılda Bartın'da kullanılan kadın giyim eşyaları ve sayıları verilmiştir.

Tablo 1: 19. yy Bartın kadın tereke kayıtlarında yer alan kıyafet türleri ve say1lar1

\begin{tabular}{|c|c|c|}
\hline & Ürün türü & Adet \\
\hline \multirow[t]{4}{*}{1} & Abaniye & 6 \\
\hline & Abaniye burgu & 1 \\
\hline & Çubuklu abaniye & 1 \\
\hline & Eskilik abaniye & 1 \\
\hline \multirow[t]{4}{*}{2} & Bağlık/ Bağlak & \\
\hline & Elli bağlak ve elli uçkur & 32 \\
\hline & Koyun bağlığ1 & 42 \\
\hline & Telli bağlak & 1 \\
\hline \multirow[t]{2}{*}{3} & Börk & \\
\hline & İpek börk & 1 \\
\hline \multirow[t]{7}{*}{4} & Ceket & \\
\hline & Basma ceket & 2 \\
\hline & Basma ceket (Köhne) & 4 \\
\hline & Kadife ceket & 1 \\
\hline & Şazen ceket & 2 \\
\hline & Telli ceket & 1 \\
\hline & Yünlü ceket & 2 \\
\hline 5 & Çevre & 3 \\
\hline 6 & Çorap & 4 \\
\hline 7 & Dizlik & 3 \\
\hline 8 & Nene dizlik & 2 \\
\hline \multirow[t]{4}{*}{9} & Entari & 3 \\
\hline & Alaca entari & 1 \\
\hline & Basma entari & 1 \\
\hline & Gecelik entarisi & 3 \\
\hline
\end{tabular}


Bartın Tereke Kayıtlarına Göre 19. Yüzyılda Kadınlarda Giyim Kuşam | 201

\begin{tabular}{|c|c|c|}
\hline & Kadife entari & 1 \\
\hline & Keten gecelik entarisi & 1 \\
\hline & Kisa entari & 4 \\
\hline & Kutni entari & 2 \\
\hline & Kutni kısa entari & 2 \\
\hline & Şetârî entari & 2 \\
\hline & Telli entari/telli kısa entari & 4 \\
\hline & Uskufe entari & 2 \\
\hline 10 & Fes & 1 \\
\hline \multirow{5}{*}{11} & Gömlek & 37 \\
\hline & Bez gömlek & 50 \\
\hline & İki kanatlı gömlek & 1 \\
\hline & Cehre gömlek & 5 \\
\hline & Hüma yün Gömlek & 1 \\
\hline \multirow[t]{4}{*}{12} & Hirka & 7 \\
\hline & Keten hirka & 1 \\
\hline & Yünlü hırka & 1 \\
\hline & Aba haki hırka & 1 \\
\hline \multirow[t]{2}{*}{13} & İşlik/İşlek & \\
\hline & Telli işlik & 3 \\
\hline 14 & Kafes-i bedeni & 1 \\
\hline 15 & Kemer kuşak & 2 \\
\hline \multirow[t]{4}{*}{16} & Kundura & 2 \\
\hline & Fotin kundura & 1 \\
\hline & İskarpin kundura & 1 \\
\hline & Sirma iskarpin kundura & 1 \\
\hline \multirow[t]{3}{*}{17} & Kuşak & \\
\hline & Kemer kuşak & 2 \\
\hline & Yün kuşak & 1 \\
\hline 18 & Mendil & 2 \\
\hline 19 & Nalın & 1 \\
\hline 20 & Nakışlı paça & 6 \\
\hline 21 & Pabuç & 2 \\
\hline 22 & Puşi & 5 \\
\hline \multirow[t]{2}{*}{23} & Peştamal & 3 \\
\hline & Adi peştamal & 1 \\
\hline
\end{tabular}




\begin{tabular}{|c|c|c|}
\hline & İpekli peştamal & 2 \\
\hline & Müstamel peştemal & 1 \\
\hline & Telli peştamal & 3 \\
\hline 24 & Şal & 1 \\
\hline \multirow[t]{11}{*}{25} & Şalvar & \\
\hline & Basma şalvar & 3 \\
\hline & Canfes şalvar & 5 \\
\hline & Kadife şalvar & 6 \\
\hline & Mantin şalvar & 1 \\
\hline & Satentilyon şalvar & 2 \\
\hline & Şayak şalvar & 1 \\
\hline & Şazen şalvar & 2 \\
\hline & Talasi şalvar & 1 \\
\hline & Telli şalvar & 2 \\
\hline & Yünlü şalvar & 8 \\
\hline \multirow[t]{6}{*}{26} & Uçkur & 23 \\
\hline & Allı uçkur & 4 \\
\hline & İşlemeli uçkur & 8 \\
\hline & Elli bağlık ve elli uçkur & 32 \\
\hline & Çift uçgur & 5 \\
\hline & Ağar uçkur & 2 \\
\hline \multirow[t]{7}{*}{27} & Yağlık & 9 \\
\hline & Ağar yağlık & 6 \\
\hline & Allı yağlık & 2 \\
\hline & Gül yağllğ 1 & 79 \\
\hline & Koyun yağlı̆̆ & 42 \\
\hline & Sab tesmeli yağlı̆̆ & 5 \\
\hline & Yazı tesmeli yağlığı & 8 \\
\hline 28 & Yaşmak örtüsü & 1 \\
\hline 29 & Yazma & 12 \\
\hline \multirow[t]{6}{*}{30} & Yelek & 2 \\
\hline & Alaca yelek & 3 \\
\hline & Altıparmak kutni yelek & 1 \\
\hline & İpek büzgülü kadife yelek & 1 \\
\hline & İşli canfes yelek & 2 \\
\hline & Kadife kısa yelek & 2 \\
\hline
\end{tabular}




\begin{tabular}{|l|l|l|}
\hline & Kutni kısa yelek & 1 \\
\hline & Kutni yelek & 10 \\
\hline & Sevai yelek & 1 \\
\hline & Şetali/ şitali yelek & 2 \\
\hline & Telli yelek & 15 \\
\hline & Uskufe yelek & 3 \\
\hline
\end{tabular}

Terekelerde ismi geçen kumaş türleri arasında yünlü, pamuklu ve ipekli dokumalar bulunmaktadır. Bartınlı kadınların kullanmış oldukları kumaş çeşitleri şunlardır: Basma, yünlü, telli, kadife, kutnu, ipekli, alaca, satentilyon, şetali, talasi, canfes, uskufe, şayak, şazen, keten, sevai, ahmediye. Pamuklu dokumalar arasında basma ağırlıkta yer almaktadır. İpekli kumaş olarak kutnî, ipekli, satentilyon, sıklıkla tekrar edilmektedir. Özellikle kutni, hazırlanılan giysinin de ismini alarak ceket, yelek ve elbise yapımında kullanılmıştır. Bartın yöresinde tel işlemeli kumaşlar yoğun kullanılmıştır. Tereke kayıtlarında telli şeklinde kaydedilmiş bağlak, ceket, yelek, entari, şalvar, entari, işlik ve peştamal bulunmaktadır. Zengin ya da fakir olsun terekelerde bu kumaşların kullanıldığına rastlamaktayız. Fakat zengin ailelerde ipekli kumaş çeşitlerinin daha fazla olduğu görülmektedir (BOA. BŞS. 808: 68). Terekelerdeki bazı kumaşlar ve aksesuarlar özellikle zenginler tarafından kullanılmaktaydı ve sosyal statüyü belirtmektedir. Elbise çeşitleri bu kişilerin gelir düzeyini gösterir şekilde pahalılaşmakta ve fazlalaşmaktadır (Oğuz, 2011, s. 115).

\subsection{Başa Takılan Giyim Parçaları}

Bartın terekelerine göre başa takılan giyim parçaları on iki çeşittir. Bağlak, yağlık, çevre, puşi, yazma, çatkı, telli örtü, telli bez, telli yemeni, abaniye, fes ve börk olarak karşımıza çıkmaktadır. Bağlak; yemeni, renkli basmadan yapılan başörtüsüne verilen isimdir (Dağlı, 2007, s. 39). Bu giysi türü, Ömer Ağa oğlu Ali'nin zevcesi Penbe Hatun'un terekesinde telli bağlak olarak adiyla kaydedilmiştir (BOA. BŞS. 807: 61-62/149). Yağlık terimi ise, giyim tarihinde iki farklı anlamda kullanılmaktadır. Yağlı elleri ve ağızı silmeye mahsus el bezi, peşkir manasına geldiği gibi çevre ya da yemeni olarak tabir edilen başörtüsüne de yağlık denilmektedir (Dağlı, 2007, s. 278). Bartın sicillerinde yer alan yağlık çeşitleri koyun, allı, gül, ağır olarak sınıflandırılmıştır. Sayılarının fazla olması dikkat çekicidir. Yağlık olarak 9 adet, koyun yağlığı 42, gül yağlığı 79 adettir (Bkz. Tablo 1). 53 adet gül yağlığ 1 Cedid Bekir köyünden Ömer Ağa oğlu Mustafa'nın zevcesi Fatıma'nın terekesinde yer alır (BOA. BŞS. 802: 75/25). Fatıma'nın terekesinde yağlık sayısının fazla olması satışını yaptığını düşündürmektedir. Başörtüsü 
anlamına gelen çevre (Koçu, 1996, s. 71 ) terekelerde yer bir diğer baş giysisidir. Kıran Karyesi'nden Halil oğlu kerimesi Hatice bint-i Mahmud'un zevcesinin terekesinde 3 adet yer alır (BOA. BŞS. 802: 9/30). Terekelerde yer alan bir diğer baş giysisi yazmadır. Başa takılan renkli, çiçekli, genellikle bindallı renginde ince tülbente yazma denir (Dağlı, 2007, s. 267). Terekelerde 12 adet yazma kaydedilmiştir. Puşi olarak adlandırılan kadınların başlarına örttükleri, kenarları saçaklı, ipek, pamuk veya yünden başörtüsünün (Dağlı, 2007, s.226) Bartın yöresinde kullanıldığı anlaşılmaktadır. 5 adet puşi tespit edilmiştir (Bkz. Tablo 1). Yöreye özgü baş giysilerinden bir diğeri olan çatkı, Düzce-Bolu-Bartın-Zonguldak bölgesinde kırmızı, pullu ve işlemeli gelin duvağıdır. Bartın çatkısı, tülbent üzerine puldan işleme başörtüsü şeklindedir. Genç kızlar düğünlerde başlarına giydikleri fesin üzerine örterek kullanırlardı (Bartın Halk Kültürü, 1996, s. 1191). Tereke kayıtlarını incelediğimizde bu isimle bir veri bulunmadığı görülür. Yörede çokça kullanılan ancak yine kayıtlarda yer almayan bir diğer ürün telli örtüdür. Tel kırma işi ile hazırlanmış bu örtüler, Bartınlı kadınların özel günlerde ve düğünlerde kıyafetlerini tamamlayan önemli bir aksesuardı. 19. yüzyılda genç kızlar başlarını telli yazmalar ile örtüp üstüne de değerli mücevherlerle süslenmiş bir taç koyarlardı (Bartın Halk Kültürü, 1996, s. 1183). Yöre ağzında çatkı ya da telli örtü olarak bilinen bu giysi çeşidinin sicillerde farklı bir isimle yer aldığı anlaşılıyor. Baş giysileri arasında sayacağımız bir diğer ürün abaniyedir. Ağbani, atkısı pamuk, çözgüsü ipek sarıya yakın beyaz zemin üzerine açık turuncu ipekli süslemeleri bulunan kumaş çeşididir. Halk ve dokumacılar arasında abani olarak geçer (Özbel, 1948, s. 18). İstanbul, Bursa, Bağdat, Halep ve Hindistan'da dokuma kumaş yapıldığı yere, desenine ve rengine göre adlandırılmıştır. Zemini beyaz, dallan safran renginde kasnak işlemeli bir çeşit kumaştır (Özkarcı, 1995, s. 289). Daha çok sarık olarak kullanılan abani kumaş perde, yorgan yüzü, başörtüsü, bohça, kundak, sarık bezi ve kadın giysi yapımında geniş ölçüde kullanılmıştır (Yardımcısı, 2016, s. 203). Bartın' daki örnekleri başa ve omuzlara sarılan dış giysisi şeklindedir. Bartın'da tercih edilen abaniyeler ipek ve pamuk karışımı beyaz ve sarı zemin üzerine, gergefte sarı ipek iplikle çeşitli motiflerle işlenmiştir (Bartın Halk Kültürü, 1996, s. 1184). Terekelerde 9 adet abaniye ismine rastlanır (Bkz. Tablo 1). Son olarak Bartın kadın tereklerinde yer alan iki baş giysisine değinmek gerekir. Bunlar, kayıtlarda birer adet yer alan fes ve börktür. Fes, Adamescidli Hatice Hatun'un terekesinde karşımıza çıkmaktadır (BOA. BŞS. 808: 68). Fes Bartın kıyafetinde önemli bir yere sahiptir. Kadınların fesi erkeklerin giydikleri gibi kalın yün kumaştan koyu kırmızı renkte, 3-4 santim derinliğinde adeta bir bere görünümündeydi (Bartın Halk Kültürü, 1996, s. 1191). Börk ise Meclis 
Mahallesi'nden Ömer Ağa oğlu Ali zevcesi Penbe Hatun'un terekesinde ipek börk olarak yer alır (BOA. BŞS. 807:61-62/149).

\subsection{Bedene Giyilen Giyim Parçaları}

Bartın'da bedene giyilen geleneksel kadın kıyafetlerini 5 başlık altında değerlendirmek mümkündür. Yelek, entari, ceket, şalvar, gömlek/göynek şeklinde sınıflandırma yapılabilir. Bu giysilerin biçimleri boldu ve kadınların vücutları bu parçalar içinde belirsiz bir halde kalırdı. Bu nedenle giyim parçalarında kullanılan kumaş miktarı fazladır. Kıyafetlerin süslü olmalarına da önem verilirdi. Bedene giyilen parçaların çoğu işlemeler ile zenginleştirilmiştir. Anadolu'nun diğer bölgelerinde de benzer özellikler görülmektedir.

Bartın sicil kayıtlarında dört çeşit yelek ismi geçmektedir. Telli, kutni/kutnu, uskufe ve alaca yelek olarak sınıflandırma yapılmıştır. Toplamda 43 yelek kaydedilmiştir. Bunlardan 15'i telli, 11'i kutnu, 3'ü uskufe, 3'ü kadife, 2'si canfes, 1'i sevai, 2'si şitali ve 3 adeti alaca yelektir (Bkz. Tablo 1).

Değindiğimiz gibi Bartın yöresinde kadın giysisi olarak kullanılan uskufe yelek geleneksel giysi türleri arasında ön plana çıkmaktadır. Ancak terekeler göz önüne alındığında 3 adet uskufe yelek kaydının tutulduğu görülür. Adamescidili Hatice Hatun, Meclis Mahallesi'nden Hüseyin'in zevcesi Ayşe ve Mektep Mahallesi'nde Meydanlizade Ahmet Ağa'nın zevcesi Hayriye Hatun'un terekesinde uskufe yelek kaydı bulunmaktadır (BOA. BŞS. 808:68; BOA. BŞS. 808:426; BOA. BŞS.807: 89/572). Uskufe yeleklerin kumaşının özelliğinden dolayı telli yelek olarak kaydedilmiş olma ihtimali yüksektir. Nitekim terekelerde sayı bakımından en fazla telli yeleğin bulunması bu ihtimali kuvvetlendirmektedir. Neredeyse tüm tereke sahibi kadınların en az bir telli yeleği bulunmaktadır. Gelir durumunda yaşanan farklılıkların bu sonucu değiştirmediği görülür. Maddi değer bakımından en kıymetlisi Kıran Karyesinden Halil oğlu kerimesi Hatice bint-i Mahmud'un zevcesine ait 140 kuruşluk telli yelektir (BOA. BŞS.802: 9/30). En ucuzu ise Şiremir Çavuş Karyesinde Çavuşoğlu Kerimesi Fatma bint-i Halil'e ait 40 kuruşluk telli yelektir (BOA. BŞS. 807: 21/54).

Sayıca fazla olan diğer bir yelek çeşidi kutnudur. Uskufenin bel hizasına kadar olanlarına kutnu denmektedir. Parlak ve mat çizgili desenlere sahip bir kumaş türü olan kutnu bir giysi türünün ismi olarak da geçmiştir. Kısa kollu olabildiği gibi uzun kollu olanları da mevcuttur (Bartın Halk Kültürü, 1996, s. 1190). Değerinin diğer yelek türlerine göre daha düşük olduğu anlaşılır. Bakkal Mahallesi'nden Demirci Ahmed oğlu Kerimesi Aişe'nin kutni yeleği için 13 kuruş 20 para değer biçilmiştir (BOA. BŞS. 802: 24-25/86). Terekede geçen diğer yelek türleri kumaş 
çeşidine göre isimlendirilmiştir. 3'ü kadife, 2'si canfes, 1'i sevai, 2'si şitali ve 3'ü alaca yelektir (Bkz. Tablo 1).

Bartın sicil kayıtlarında yer alan bir diğer giysi türü entaridir. Terekelerde 7 çeşit entari ismi geçmektedir. Telli, kutni, basma, alaca, kadife, şetari, kutni kısa entari entari olarak sınıflandırma yapılmıştır. Toplamda 26 entari kaydedilmiştir. Bunlardan 1'i alaca, 1'i basma, 3'ü gecelik entarisi, 1'i kadife, 4'ü kısa entari, 2'si kutni entari, 2'ai kutni kısa entari, 2'si şetari entari, 4'ü telli entari/telli kısa entari ve 2'si uskufe entaridir (Bkz. Tablo 1). Bartın'da kullanılan entari çeşidi üretilen kumaş türüne göre isimlendirilmiştir.

Yörede kullanılan şalvar örneklerinin nerdeyse tamamı Adamescidli Hatice Hatun'un terekesinde bulunmaktadır (BOA. BŞS. 808: 68). Satentilyon şalvar, talasi şalvar, canfes şalvar, mantin şalvar, telli şalvar, kadife şalvar bulunmaktadır. Şalvar türlerinin hepsinin aynı terekede yer alması fiyatlandırılma yapılırken dikkat edilen hususların neler olduğu hakkında fikir vermektedir. Örneğin şalvarlar arasında en kıymetlisi satentilyon şalvardır. Ancak bunun da bir standartta olmadığı görülüyor ki iki ayrı kalemde yazılan satentilyon şalvara 60 ve 81 kuruş değer biçilmiştir (BOA. BŞS. 808: 68). Yukarıda belirttiğimiz giysinin kullanılmış olması, kumaşının eski ya da yeni olması aynı kıyafetin değişik fiyatlarla belirlenmesine sebep oluyordu. Ancak verilen her iki fiyatın yüksek olması diğer türdeki şalvarlara göre kıymetli olduğunu gösteriyor. Nitekim 1 adet şetâlî yelek 1 adet talasi şalvar 50 kuruş, 1 adet canfes şalvar 35 kuruş, 1 adet mantin şalvar 50 kuruş, 1 adet telli şalvar 65 kuruş ve 1 adet kadife şalvara 30 kuruş değer biçilmiştir. Meclis Mahallesi sakinlerinden Ayşe Hanım'ın tereke kaydında da yöredeki şalvar türlerinin çoğu bulunmaktadır (BOA. BŞS. 808: 426). Ve bu şalvarlar ceketleri ile birlikte takım olarak kaydedilmiştir. Kadife şalvar, telli şalvar, şazen şalvar, yünlü şalvar örnekleri ceket ile birlikte hesap edilmiştir. Fiyatlarına baktığımız zaman bu türler arasında en kıymetlisi kadife şalvar takımıdır. 80 kuruş 20 para tutarındadır. Ardından iki âdeti 78 kuruş 20 paraya denk gelen telli şalvar gelmektedir. En ucuzu iki âdeti 20 kuruş 10 para ile şazen şalvar ve ceketidir (BOA. BŞS. 808: 426).

\subsection{Giysi Tamamlayıcısı Olan Parçalar}

Tereke defterlerinde giysilerin tamamlayıcısı olarak sayabileceğimiz kuşak, uçkur, kemer, peştamal, şal ve yaşmak örtüsüne rastlamaktayız. Eski Türk giyim kuşamında hem erkek hem kadın belinde önemli bir yeri olan kuşak, beli sıkı tutmak için sarılan uzun ve dar kumaşın ismidir. Kadın giyim kuşamında entariler üstüne sarılan dış kuşaklar, özellikle şal kuşaklar giysinin tamamlayıcı unsurudur. $\mathrm{Bu}$ kuşaklar bele ancak bir defa dolanır ve önden bir düğümle bağlanırdı (Koçu, 
1969, s. 161). Bartın kıyafetleri arasında yer bulan kuşaklar çeşitli renklerde ipekli kumaşlardan yapılmıştır. Yurdumuzun birçok yöresinde kullanılan kuşaklarla aynıdır. Yörede uskufe yeleğin üstüne acemşal denen büyük kuşak sarılırdı. Genç kızlar kuşağı önden, kadınlar ise arkadan bağlarken erkeklerde kuşak kullanırdı. Yaşlı veya fakir erkeklerde beyaz yün kuşak, zengin ve süse meraklı gençlerde ise "tarblus kuşağı" denilen çok renkli ipek kuşak kullanılır (Murat, 2002, s. 88). Tereke kayıtlarında 1 adet yün kuşak 2 adet kemer kuşak kaydedilmiştir. Yün kuşak Amasra Nahiyesi Sürmekir Mahallesi'nden Fatma Hatun'un terekesinde diğer 2 kemer kuşak Adamescidli Hatice Hatun'un terekesinde bulunur (BOA. BŞS. 807: 18/45; BOA. BŞS. 808: 68).

Kemer kuşak olarak kaydedilen ürünün kemer olma ihtimali yüksektir. Bartın'da özellikle uskufe yeleklerin üzerine kemer kullanılmaktaydı. Bu kemerler ekseriyetle pamuklu, keten ya da sarı kalın yollu dokumadan yapılırdı. Kumaşa arkadan metal köprüler ile tutturulan tokalar birbirlerine de iki çengel ile birleştirilmiştir (Bartın Halk Kültürü, 1996, s. 1182). Terekelere baktığımız zaman oldukça az sayıda kemer kaydına rastlarız. Geleneksel giyimde uskufe yeleğin kemer ile kullanılması yaygın iken bu durum terekelere yansımamıştır. Kemer kuşak olarak kaydedilen 2 adet kayıt mevcuttur. Her iki üründe Adamescidli Hatice Hatun'a aittir (BOA. BŞS. 808: 68).

Vücudun belden aşağı alt kısmına geçirilip giyilen her şey belden uçkur denilen ince kuşakla bağlanarak tutulurdu. Uçkurlar hem örgü hem kumaştan olurdu; şalvar uçkurları 3-4 parmak genişliğinde olurdu ve uçları ipekle hatta sırma ile işlenerek süslenirdi. Öyle ki şalvar giyilip uçkur bağladıktan sonra, işlemeli uçları bir süs olarak şalvarın önüne sarkıtılırdı (Koçu, 1969, s. 236). Bartın terekelerinde uçkur sayısı oldukça fazladır. 74 adet uçkur geçmektedir. Allı, işlemeli, ağar, çift ve elli uçkur şeklinde çeşitleri sıralanmıştır (Bkz. Tablo 1).

Giysi tamamlayıcısı olarak saydığımız bir diğer ürün türü peştamaldır. Bartın geleneksel kadın kıyafetleri arasında kullanılan peştamallar, bele bağlanan ve vücudun belden aşağı kısmını örten bez anlamına gelmektedir. Bartın peştamalları, lacivert pamuk iplik dokuma üzerine kırmızı ipek iplikten dokunmuş olup, kırmızı dokumanın üzerinde beyaz simli genişçe çizgiler yer almaktadır (Bartın Halk Kültürü, 1996, s.1180). Tereke kayıtlarında 10 adet peştamal kaydedilmiştir. İpekli, telli, adi ve müstamel peştamal olarak kaydedilen ürünler kumaş türü ve yıpranmışlık durumu bakımından sınıflandırılmıştır. Değer bakımından en kıymetlisi 40 kuruş ile telli peştemaldir. Şiremir Çavuş Karyesinden Çavuşoğlu Kerimesi Fatma'nın terekesinde 1 adet bulunmaktadır (BOA. BŞS. 807: 21/54). 
Bartın terekelerinde karşımıza yaşmak örtüsü de çıkmaktadır. Osmanlı'da Müslüman kadınların sokakta ferace giydikleri zaman yüzlerine örttükleri yaşmak, tek bir terekede 1 adet olarak kaydedilmiştir (BOA. BŞS. 808: 426). Bartın'da yaşmağın fazla kullanılmadığını söyleyebiliriz.

Bartın'da giysi tamamlayıcısı kategorisine dâhil edebileceğimiz bir diğer ürün elmaslı çelenktir. Tereke kayıtlarında elmaslı çelenk olarak geçen (BOA. BŞS. 808:68) yörede gelin tacı olarak da adlandırılan ve düğünlerde gelin takısı olarak kullanılan bir aksesuardır. Yerel kaynaklara göre bu aksesuarın düğünler ya da özel günlerde Bartınlı kadınların geleneksel kıyafetlerinin tamamlayıcısı olarak kullanımı oldukça yaygındır (Bartın Halk Kültürü; Çetin Asma, 2011). Ancak tereke kayıtlarında sadece Adamescidli Hatice Hatun'un terekesinde elmaslı çelenge rastlıyoruz. Bir âdeti 300 kuruş olarak fiyatlandırılmış döneminin kıymetli bir aksesuarıdır (BOA. BŞS. 808: 68). Bu aksesuara Müslüman kadın terekelerinde tek bir kişide rastlanmış olması bununla beraber yerel kaynaklarda kullanımının oldukça yaygın olduğunun vurgulanması bu aksesuarın -daha ziyadegayrimüslim kadınlar tarafından kullandığını düşündürmektedir. Zamanla Bartınlı Müslüman kadınlar arasında da talep gördüğü muhtemeldir.

Tablo 2: 19. Yüzyılda da Kadın Terekelerine Göre Bartın'ın Sosyal ve Ekonomik Durumu

\begin{tabular}{|c|c|c|c|c|c|}
\hline \multicolumn{6}{|c|}{$\begin{array}{l}\text { Tablo 2: Bartın şer'iye sicillerinde tespit edilen kadın terekelerinde gelir } \\
\text { durumu }\end{array}$} \\
\hline $\begin{array}{l}\text { Tereke } \\
\text { kaydi }\end{array}$ & $\begin{array}{l}\text { Toplam } \\
\text { tereke } \\
\text { tutari }\end{array}$ & $\begin{array}{l}\text { Kiyafet } \\
\text { tutarı }\end{array}$ & $\begin{array}{l}\text { Kadın } \\
\text { takı } \\
\text { tutarı }\end{array}$ & Mahalle & Sahibeleri \\
\hline $\begin{array}{l}\text { BOA. } \\
\text { BŞS. 807: } \\
18 / 45\end{array}$ & & $\begin{array}{l}\quad 617,5 \\
\text { kuruş }\end{array}$ & & \begin{tabular}{l}
\multicolumn{1}{|c}{ Amasra } \\
Nahiyesi \\
Sürmekir \\
Mahallesi
\end{tabular} & \begin{tabular}{|lr}
\multicolumn{2}{|c}{ Kantarcı } \\
oğlu $\quad$ Emin'in, \\
Ahd & Karyesi \\
ahalisinden \\
Seranlı & oğlu \\
İlyas'ın & kız \\
kardeşi & Fatma \\
Hatun & \\
\end{tabular} \\
\hline $\begin{array}{l}\text { BOA. } \\
\text { BŞS. 807: } \\
21 / 54\end{array}$ & 6426 & 190 & & $\begin{array}{l}\quad \text { Şiremir } \\
\text { Çavuş } \\
\text { Karyesinde }\end{array}$ & $\begin{array}{l}\text { Çavuşoğlu } \\
\text { kerimesi Fatma }\end{array}$ \\
\hline
\end{tabular}


Bartın Tereke Kayıtlarına Göre 19. Yüzyılda Kadınlarda Giyim Kuşam | 209

\begin{tabular}{|c|c|c|c|c|c|}
\hline $\begin{array}{r}\text { BOA. } \\
\text { BŞS. 807: } \\
61-62 / 149\end{array}$ & \multicolumn{3}{|c|}{ Fiyat belirtilmemiş } & $\begin{array}{l}\text { Meclis } \\
\text { Mahallesi }\end{array}$ & $\begin{array}{l}\text { Ömer Ağa } \\
\text { oğlu Ali zevcesi } \\
\text { Penbe Hatun }\end{array}$ \\
\hline $\begin{array}{l}\text { BOA. } \\
\text { BŞS. 807: } \\
89 / 572\end{array}$ & 5122 & $\begin{array}{l}1585 \\
\text { kuruş } 40 \\
\text { para }\end{array}$ & 685 & $\begin{array}{c}\text { Mektep } \\
\text { Mahallesinde }\end{array}$ & \begin{tabular}{l}
\multicolumn{2}{c}{ Tirtılzade } \\
Halil Efendi \\
Kerimesi ve \\
Meydanlızade \\
Ahmet Ağa \\
zevcesi Hayriye \\
Hatun
\end{tabular} \\
\hline $\begin{array}{l}\text { BOA. } \\
\text { BŞS. 808: } \\
68\end{array}$ & \begin{tabular}{l}
\multicolumn{2}{r}{15071} \\
kuruş 10 \\
para
\end{tabular} & $\begin{array}{l}2231 \\
\text { kuruş } 50 \\
\text { para }\end{array}$ & 3950 & \begin{tabular}{l}
\multicolumn{1}{c}{ Bartın } \\
Kasabasının \\
Adamescid \\
Mahallesi
\end{tabular} & $\begin{array}{l}\quad \text { Vefat eden } \\
\text { Hacı Kara } \\
\text { Hüseyinoğlu } \\
\text { Mehmed } \\
\text { Efendi zevcesi } \\
\text { Hatice Hâtûn } \\
\text { bint-i Daver }\end{array}$ \\
\hline $\begin{array}{l}\text { BOA. } \\
\text { BŞS. 808: } \\
85\end{array}$ & \begin{tabular}{l}
\multicolumn{2}{c}{841} \\
kuruş 10 \\
para
\end{tabular} & 339 & & $\begin{array}{l}\quad \text { Bartın } \\
\text { nevâhîsinden } \\
\text { Gölpazarı } \\
\text { nâhiyesinin } \\
\text { Kizılkum karyesi }\end{array}$ & $\begin{array}{l}\quad \text { Kara } \\
\text { Hüseyinoğlu } \\
\text { Molla Ramazan } \\
\text { zevcesi Hadice } \\
\text { Hatun }\end{array}$ \\
\hline $\begin{array}{l}\text { BOA. } \\
\text { BŞS. 808: } \\
131\end{array}$ & \begin{tabular}{l}
\multicolumn{2}{c}{5422} \\
kuruş 36 \\
para
\end{tabular} & 535 & & \begin{tabular}{|l}
\multicolumn{1}{|c}{ Bartın } \\
Kasabasının \\
Adamescid \\
Mahallesi \\
\end{tabular} & $\begin{array}{l}\text { Hazînedâr- } \\
\text { zâde Ömer bin } \\
\text { Hüseyin'in } \\
\text { zevcesi }\end{array}$ \\
\hline $\begin{array}{l}\text { BOA. } \\
\text { BŞS. 808: } \\
426\end{array}$ & 3360 & 706 & & $\begin{array}{l}\text { Bartın } \\
\text { Kasabasının } \\
\text { Meclis Mahallesi }\end{array}$ & \begin{tabular}{l}
\multicolumn{2}{c}{ Tosunoğlu } \\
kerîmesi ve \\
Asmalığlu \\
Hüseyin \\
zevcesi Ayşe \\
bint-i Mustafa
\end{tabular} \\
\hline
\end{tabular}




\begin{tabular}{|c|c|c|c|c|c|}
\hline $\begin{array}{l}\text { BOA. } \\
\text { BŞS. 802: } \\
9 / 30\end{array}$ & \begin{tabular}{|l}
\multicolumn{2}{c}{1398} \\
kuruş 32 \\
para
\end{tabular} & 567 & 276 & \begin{tabular}{l}
\multicolumn{2}{|c}{ Millet } \\
Divanı/ Kıran \\
Karyesi
\end{tabular} & $\begin{array}{l}\quad \text { Halil oğlu } \\
\text { kerimesi Hatice } \\
\text { bint-i Mahmud } \\
\text { zevcesi }\end{array}$ \\
\hline $\begin{array}{l}\text { BOA. } \\
\text { BŞS. 802: } \\
24-25 / 86\end{array}$ & \begin{tabular}{l}
\multicolumn{2}{c}{2172} \\
kuruş 35 \\
para
\end{tabular} & $\begin{array}{l}\quad 815 \\
\text { kuruş } \\
\text { 235 para }\end{array}$ & & $\begin{array}{l}\text { Bartın } \\
\text { Mahallatı/Bakkal } \\
\text { Mahallesi }\end{array}$ & \begin{tabular}{l}
\multicolumn{2}{c}{ Demirci } \\
Ahmed oğlu \\
kerimesi Aişe
\end{tabular} \\
\hline $\begin{array}{l}\text { BOA. } \\
\text { BŞS. 802: } \\
75 / 275\end{array}$ & 2712 & $\begin{array}{l}\quad 984 \\
\text { kuruş } \\
280 \text { para }\end{array}$ & & $\begin{array}{l}\text { Bartın } \\
\text { mahallatı / Cedid } \\
\text { Bekir Kalesi }\end{array}$ & $\begin{array}{l}\text { Demirci } \\
\text { Ahmed oğlu } \\
\text { Kerimesi Aişe }\end{array}$ \\
\hline $\begin{array}{r}\text { BOA. } \\
\text { BŞS. 805: } \\
65-66 / 121\end{array}$ & $\begin{array}{l}3580 \\
\text { kuruş } 30 \\
\text { para }\end{array}$ & $\begin{array}{l}\quad 342 \\
\text { kuruş } 90 \\
\text { para }\end{array}$ & & $\begin{array}{l}\text { Bartın } \\
\text { mahallatı, } \\
\text { Bakkal Mahallesi }\end{array}$ & $\begin{array}{l}\text { Çınçın oğlu } \\
\text { Ahmed..... } \\
\text { (okunmuyor) }\end{array}$ \\
\hline
\end{tabular}

Kadın terekeleri üzerinden Bartın şehrinin genel sosyal yapısına dair çıkarımlar da yapabilmekteyiz. Sahip olunan ürünler, miktarları ve tutarları, kişilerin yaşadıkları mahalleler toplumun sosyal ve ekonomik durumları hakkında ipuçları verebilmektedir. Elimizdeki bulgular üzerinden şu şekilde değerlendirme yapabiliriz.

Bartın tereke kayıtlarına göre en zengin tereke sahibi kadın, Adamescidi Mahallesi sakinlerinden Hacı Kara Hüseyinoğlu Mehmed Efendi'nin hanımı Hatice Hatun'dur. 15071 kuruş 10 para değerindeki terekesiyle Bartın şer'iye sicilleri içerisinde en yüksek meblağlı tutara sahiptir. Terekesinin 2231 kuruş 50 parası kıyafetlere ayrılmıştır. Aynı zamanda 3950 kuruşluk takıları bulunmaktadır (BOA. BŞS. 808: 68). Hatice Hatun'un terekesinde yörede kullanılan giysi örneklerinin neredeyse hepsine dair örnek bulunmaktadır. En düşük tutarlı tereke sahibi ise toplamda 841 kuruş 10 para ile Gölpazarı nahiyesine bağlı Kızılkum köyünden Kara Hüseyinoğlu Molla Ramazan zevcesi Hadice Hatun'dur. Terekesinde kıyafetlere ayrılan miktar 339 kuruştur (BOA. BŞS. 808: 85).

Toplumun iki uç kesiminin kıyafete ayırdıkları bütçeleri anlayabilmek adına en zengin ve en fakir terekeleri kıyaslamaya gidersek; Adamescidi Mahallesi sakinlerinden Hatice Hatun ile Kızılkum köyünden Hatice Hatun arasında 14.230 kuruşluk fark bulunmaktadır. Adamescidli Hatice Hatun kıyafete 6 buçuk kat 
daha fazla bütçe ayırmıştır. Bunun yanında takılar ve ziynet eşyası bakımından iki tereke arasındaki önemli fark gözükmektedir. Kızılkumlu Hatice Hatun'un 57 kuruşluk bir çift küpesi bulurken Adamescidli Hatice Hatun'un 3950 kuruşluk takı ve ziynet eşyasına sahiptir. Bu veriler iki tereke sahibi arasında büyük bir ekonomik farklılık olduğunu gösteriyor. Biri Bartın merkezde Adamescidi Mahallesi'nde yaşamakta diğeri ise Amasra nahiyesinin köylerden biri olan Kızılkum karyesinde ikamet etmektedir. Kızılkumlu Hatice Hanım'ın terekeye kaydedilmeye değer sayılabilecek olarak sadece bir kat özel gün kıyafetine sahiptir (BOA. BŞS. 808: 85). Birer adet şetari entari, şal ve kutni yeleği mevcuttur. Bununla birlikte diğer terekelerde yer almayan ve kullanım alanını tespit edemediğimiz nakışlı paça ve kafes-i bedeni türündeki giysiler yine bu terekede bulunmaktadır. Adamsecidli Hatice Hatun'un ise yukarıda belirttiğimiz gibi yöreye ait giysi türlerinin hemen hepsi terekesinde yer almıştır.

Ortalama terekeye sahip olanlar arasında 5122 kuruş ile Mektep Mahallesi sakinlerinden Tirtılzade Halil Efendi Kerimesi ve Meydanlızade Ahmet Ağa zevcesi Hayriye Hatun örnek verilebilir. Hayriye Hatun 1585 kuruş 40 para tutarında kıyafete ve 685 kuruş değerinde takıya sahiptir. Telli yelek, uskufe yelek, kutni yelek, kısa entari, kadife şalvar, kadife ceket, basma ceket, gömlek, yazma gibi yörenin genel mahiyette kullanılan giyim türleri terekesinde bulunmaktadır (BOA. BŞS. 807: 89/572).

Sosyal statü açısından zengin ve fakir olan tereke sahiplerini göz önünde bulundurduğumuzda giyim alışkanlıkları bakımından büyük farklılıkların olmadığı görülür. Aradaki en önemli fark, zengin terekelerinden eşya sayılarının fazla olması ve eşyalara daha yüksek fiyat biçilmesidir. Bu durum zengin ailelerin elindeki giysilerin yıpranma oranlarının daha az olması ve kaliteli kumaştan imal edilmelerinden kaynaklandığı düşünülebilir. Diğer bir husus zengin ailelerinin terekelerinde aksesuar olarak kullanılan parçaların daha fazla olmasıdır. Başa takılan giysilerden yağlık ve yazma gibi eşyalar çeşit açısından daha fazladır. Örneğin en zengin terekeye sahip Hatice'nin terekesinde değeri 300 kuruş olan elmaslı çelenk bulunmaktadır. Düğün ve özel günlerde kadınların başında bulunan bu mücevher tek bir terekede karşımıza çıkmaktadır. Kadınların kendi aralarında ödünç alarak ortak kullandıkları bu aksesuarın geleneksel Bartın kadın giyiminin önemli bir tamamlayıcısı olduğu aşikârdır. Tereke kayıtlarında sadece 1 adet bulunması şaşırtıcıdır.

Ürünlerin maddi değerlerini o günün piyasasına göre anlayabilmemiz açısından 5 tane terekede yer alan ziynet eşyalarının fiyatlarından bilgi sahibi olabilmekteyiz. 
Tablo 3: 19. yüzyıl Bartın kadın tereke kayıtlarında yer alan takı ve ziynet eşyaları

\begin{tabular}{|c|c|c|c|}
\hline Ürün & Adeti & Tutarı & Sahibesi \\
\hline $\begin{array}{l}\text { Gümüş saç } \\
\text { bağ1 }\end{array}$ & 1 adet & & \multirow{8}{*}{$\begin{array}{l}\quad \text { Meclis Mahallesinden } \\
\text { Ömer Ağa oğlu Ali zevcesi } \\
\text { Penbe Hatun (BOA. BŞS. 807: } \\
\text { 61-62/149) }\end{array}$} \\
\hline $\begin{array}{c}\text { Gümüş } \\
\text { mercanlı iğne }\end{array}$ & 1 adet & & \\
\hline $\begin{array}{l}20^{\prime} \text { lik takı } \\
\text { altını }\end{array}$ & 20 adet & & \\
\hline $20^{\prime}$ lik altın & 5 adet & & \\
\hline $\begin{array}{l}\text { Sandıklı } \\
\text { kulak altını }\end{array}$ & 4 adet & & \\
\hline $\begin{array}{l}\text { Altın kaşlı } \\
\text { yüzük }\end{array}$ & 2 adet & & \\
\hline $\begin{array}{l}\text { Sandiklı } \\
\text { nısf altın }\end{array}$ & 5 adet & & \\
\hline Topaç altın & 2 adet & & \\
\hline \multicolumn{4}{|l|}{ TOPLAM } \\
\hline $\begin{array}{l}\text { Gümüş } \\
\text { bilezik }\end{array}$ & 5 adet & $\begin{array}{r}15 \\
\text { kuruş }\end{array}$ & \multirow{5}{*}{$\begin{array}{l}\text { Mektep Mahallesinden } \\
\text { Tirtılzade Halil Efendi } \\
\text { kerimesi ve Meydanlıade } \\
\text { Ahmet Ağa zevcesi Hayriye } \\
\text { Hatun (BOA. BŞS. 807: 89/572) }\end{array}$} \\
\hline $\begin{array}{l}\text { Altın küpe } \\
\text { çift }\end{array}$ & 1 adet & $\begin{array}{r}50 \\
\text { kuruş }\end{array}$ & \\
\hline $\begin{array}{l}\ddot{U}_{c ̧} \text { liradan } \\
\text { ma'mul bilezik }\end{array}$ & 1 adet & $\begin{array}{l}220 \\
\text { kuruş }\end{array}$ & \\
\hline $\begin{array}{l}\text { Yarım } \\
\text { liradan ma'mul } \\
\text { yüzük }\end{array}$ & 1 adet & $\begin{array}{l}220 \\
\text { kuruş }\end{array}$ & \\
\hline $\begin{array}{l}\text { Elmas küpe } \\
\text { çift }\end{array}$ & 1 adet & $\begin{array}{c}180 \\
\text { kuruş }\end{array}$ & \\
\hline TOPLAM & & $\begin{array}{l}685 \\
\text { kuruş }\end{array}$ & \\
\hline $\begin{array}{l}\text { Mahmudiye } \\
\text { altını }\end{array}$ & 60 adet & $\begin{array}{l}2400 \\
\text { kuruş }\end{array}$ & \\
\hline
\end{tabular}


Bartın Tereke Kayıtlarına Göre 19. Yüzyılda Kadınlarda Giyim Kuşam

213

\begin{tabular}{|c|c|c|c|}
\hline $\begin{array}{l}\text { Yirmilik } \\
\text { altin }\end{array}$ & 50 adet & $\begin{array}{l}1000 \\
\text { kuruş }\end{array}$ & \multirow{3}{*}{ 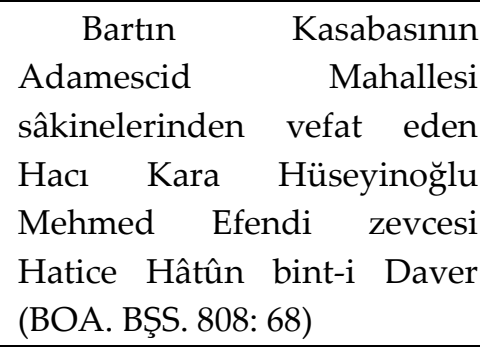 } \\
\hline Altın küpe & 1 çift & $\begin{array}{l}110 \\
\text { kuruş }\end{array}$ & \\
\hline $\begin{array}{l}\text { Saç bağında } \\
\text { olan } \quad \text { yirmilik } \\
\text { altın }\end{array}$ & 22 adet & $\begin{array}{l}440 \\
\text { kuruş }\end{array}$ & \\
\hline TOPLAM & & $\begin{array}{l}3950 \\
\text { kuruş }\end{array}$ & \\
\hline $\begin{array}{l}\text { Kulak } \\
\text { altunu }\end{array}$ & 2 adet & $\begin{array}{r}57 \\
\text { kuruş }\end{array}$ & \begin{tabular}{l}
\multicolumn{1}{c}{ Medîne-i } \\
nevâhîsinden Gölın \\
nâhiyesinin Kızıllkum karyesi \\
Kara Hüseyinoğlu Molla \\
Ramazan zevcesi Hadice \\
Hatun (BOA. BŞS. 808:85)
\end{tabular} \\
\hline $\begin{array}{l}\text { Yirmilik } \\
\text { büyük altın }\end{array}$ & 9 adet & $\begin{array}{l}216 \\
\text { kuruş }\end{array}$ & Millet Divanı/ \\
\hline $\begin{array}{l}\text { Kulak altını } \\
\text { sandıklı }\end{array}$ & 2 adet & $\begin{array}{r}60 \\
\text { kuruş }\end{array}$ & $\begin{array}{l}\text { Karyesi } \\
\quad \text { Halil oğlu kerimesi } \\
\text { Hatice bint-i Mahmud zevcesi } \\
\text { (BOA. BŞS. 802:9/30) }\end{array}$ \\
\hline TOPLAM & & $\begin{array}{l}276 \\
\text { kuruş }\end{array}$ & \\
\hline & & & \\
\hline
\end{tabular}

Yukarıda tabloda görüldüğ̈̈ üzere Adamescid Mahallesinden Hatice Hatun'un diğer terekelerden farklı olarak yüksek miktarda altını bulunmaktadır (BOA. BŞS. 808: 68). Bahsi geçen verilere göre- incelediğimiz dönem itibariyleMahmudiye altının adet fiyatı 40 kuruşa, bir adet Osmanlı lirası 110 kuruşa denk gelmektedir. Elde edilen fiyat bilgileri, giysilerin değerlerine dair çıkarımlar ve karşılaştırma yapabilme imkânı veriyor. Örneğin bir adet elmaslı çelenk 7,5 mahmudiye altını etmektedir.

Bartın yöresinde tel işlemeli kumaşlar yoğun kullanılmıştır. Aşağıdaki tabloda belirtildiği gibi telli ibaresinin kullanıldığ 10 adet giysi türü mevcuttur. Toplamda 
32 parça ürünün bulunduğu bu eşyalar şu şekildedir: 1 adet telli bağlak, 1 adet telli ceket, 3 adet telli entari, 3 adet telli işlik, 3 adet telli kısa entari, a adet telli kutni entari, 3 adet telli peştamal, 2 adet telli şalvar ve 15 adet telli yelektir. Bu giysi parçaları arasında sayıca en fazla olanı telli yelektir. Telli yeleğin uskufe yelek olarak da adlandırıldığını düşünmekteyiz. Çünkü yöreye özgü kıyafet olduğu varsayılan uskufe yeleğin terekelerde sadece 3 adet bulunması, bu isim yerine telli yelek olarak kaydedilmiş olma ihtimalini ortaya çıkarmaktadır. Ancak terekelerde bu isim altında kaydedilmeyerek kutni yelek ya da telli yelek olarak kaydedilmiştir. Maddi değeri bakımından düşündüğümüzde 140 kuruşa (BOA. BŞS. 802: 9/30) telli yelek olduğu gibi 40 kuruş (BOA. BŞS. 807: 21/54) değer biçilmiş telli yelekte mevcuttur.

Tablo 4: 19. yy Bartın kadın tereke kayıtlarında telli tabirinin kullanıldığı giysiler

\begin{tabular}{|l|l|}
\hline Ürün & Adeti \\
\hline Telli & 2 arşın \\
\hline Telli bağlak & 1 \\
\hline Telli ceket & 1 \\
\hline Telli entari & 3 \\
\hline Telli işlik & 3 \\
\hline Telli kısa entari & 3 \\
\hline Telli kutni entari & 1 \\
\hline Telli peştamal & 3 \\
\hline Telli şalvar & 2 \\
\hline Telli yelek & 15 \\
\hline
\end{tabular}

\section{SONUÇ}

Çalışma kapsamında incelenen kadın terekelerinde 30 farklı giysi çeşidine rastlanmıştır. Giyim eşyaları içerisinde bedene giyilenler eşyalar ağırlıktadır. Başörtüsü çeşitleri, yelek, entari ve şalvar terekelerde geniş bir yer tutmaktadır. Bartın geleneksel kadın kıyafeti olarak ön plana çıkan uskufe yeleğin tereke kayıtlarında sayıca fazla bulunmadığı görülür. Ürünün bu isim altında kaydedilmediği sonucuna varmak mümkündür. Giyim parçaları genellikle kullanılan kumaş türüne göre alt bir isimle tanımlanmıştır. Örneğin kadife, şazen, yünlü, kutni, ipek, canfes gibi kumaş türleri giysi isiminim önünde kullanılmıştır. Diğer taraftan giyim kuşamı tamamlayan çeşitli aksesuarlara rastlanmıştır. Aksesuarlar arasında elmaslı çelenk olarak geçen gelin tacı değer bakımından 
önem taşımaktadır. Yöreye özgü giyim kuşam parçalarından biri olarak dikkat çekicidir. Terekelerde sayıca en fazla bulunan kıyafet türü telli yelektir. Kıymet bakımından da telli yeleğin diğer ürünlerden fazla olduğu görülür. Uskufe yeleklerin telli yelek olarak kaydedilmiş olma ihtimalleri akla gelmektedir. Bartın yöresinde olan telli kumaşların kullanımının yoğun olduğu terekelerde de görülmektedir. Telli ibaresiyle kaydedilen 9 adet ürün belirtilmiştir.

Bartın geleneksel kadın kıyafetlerini değerlendirdiğimiz zaman sosyal statü açısından zengin ve fakir olan tereke sahiplerinin giyim alışkanlıkları bakımından büyük farklılıkların olmadığı anlaşılır. Zengin kadınla fakir kadının aslında aynı tarzda giyindiği ama kalite farkının ortaya çıktığı görülmektedir Aradaki en önemli fark, zengin terekelerinden miktarların fazlalığı ve kıymeti belirlenen eşyalara daha yüksek fiyat biçilmesidir. Bu durum zengin ailelerin elindeki giysilerin yıpranma oranlarının daha az olması ve kaliteli kumaştan imal edilmelerinden kaynaklanmaktadır.

\section{EXTENDED SUMMARY}

In this study, the 19th century women's clothing understanding of the Bartın region was evaluated through the wealth records included in the court registers. Court registers are the books kept by the cadilesker in Ottoman cities and referred to as court minutes. In these books, the records of wealth, also known as muhallefat, were kept in the records where the belongings of the deceased were written one by one, together with the price and quantity, under the supervision of the cadilesker. The wealth records provide data that will allow us to imagine the interior of an ordinary Ottoman family's home. This information, which differs from region to region, is one of the most important data sources for local history research. It is possible to reach different information from the wealth records, from the household tools and equipment used to the preferred clothing understanding.

In the study, 12 court registers in the Bartın Court Registers numbered 800, 802, $806,807,808$ and 810, covering the years 1892-1913, were examined. Based on the findings, evaluations were made on the women's clothing and clothing culture of the Bartin region at the end of the 19th century and the beginning of the 20th century.

Clothing culture is an important event that introduces a region in terms of its traditions and customs. Thanks to traditional clothes, it is possible to define and classify societies in terms of their ethnic identities. In this respect, traditional clothes are the cultural identity of the society to which they belong. Traditional clothes, which do not define the individual and the society they belong to, in many respects such as their social status, economic status, gender, beliefs and lifestyles, 
also carry the characteristics of a historical resource. Considering the types of clothes in the court registers, the material values of their periods, the names of their owners and the information about the places they live, the social and economic situation of Bartın was evaluated.

Almost every region of Anatolia, which has hosted different civilizations for hundreds of years, has its own unique clothing culture. Bartın region, where Greek, Armenian and Muslim population lived together during the Ottoman period, also draws attention in terms of traditional clothing culture as a result of its cultural diversity. Especially in terms of women's clothing, it is known that there are different types of clothing specific to the region. 30 different types of clothing were found in the estate books examined within the scope of the study. Among the clothing items, the items worn on the body are in weight. Types of headscarves, vests, gowns and shalwars keep a large place in the records. It is seen that the uskufe vest, which stands out in the clothing culture of Bartın and is considered to be the local women's clothing, is not found in abundance in the court registers. It is possible to conclude that the product is not registered under this name.

When we evaluate the traditional women's clothing of Bartın, it is understood that there is no great difference in the clothing habits of the wealthy and poor estate owners in terms of social status. It is seen that rich women and poor women actually dress in the same style, but there is a difference in quality. The most important difference is the excess of the rich estates and the higher prices for the items whose value is determined. This is due to the fact that the wear rate of the clothes in the hands of wealthy families is lower and they are made of quality fabric 


\section{KAYNAKÇA}

\section{Arşiv Kaynakları}

BOA. (Başbakanlık Osmanlı Arşivi) BŞS. (Bartın Şer'iye Sicilleri) Defter no. 800

BOA. BŞS. 802

BOA. BŞS. 805

BOA. BŞS. 806

BOA. BŞS. 807

BOA. BŞS. 808

BOA. BŞS. 810

\section{Araştırma ve Telif Eserleri}

Asma, Ç. (2011). Çetin Asma ile tarihe yolculuk. Bartın Belediyesi Kültür Yay.

Barkan, Ö.L. (1966). Edirne askeri kassamına ait tereke defterleri (1545-1659). Belgeler, III/(56), 1-479.

Çilsüleymanoğlu, S. (Haz.). (1996). Bartın halk kültürü: Araştırma-derleme-inceleme (C. 3). Ankara: Türk Tarih Kurumu Yay.

Dağlı, B. (2007). Kelime kazanımı üzerine bir araştırma (Kıyafet ve kumaş adları örneği) (Yüksek lezi lisans ). Erişim adresi: https://tez.yok.gov.tr/UlusalTezMerkezi/tezSorguSonucYeni.jsp

Dursun. F., Çalışan. Ç.D., \& Abanoz. G. (2019). Düzce ili geleneksel özel gün kadın giysilerinin incelenmesi. Gaziantep University Journal of Social Sciences, 18/(1), 56-74.

Faroqhi, S. (2018). Osmanlllar kültürel tarih. Ankara: Akılçelen Kitaplar.

Gündüz, M. (2019). B-188 numaralı şer'iyye siciline göre 18. yüzyıl başlarında Bursa şehrinde kadınların giyim kuşam kültürü. Uludağ Üniversitesi Fen-Edebiyat Fakültesi Sosyal Bilimler Dergisi, 20/(37), 583-608.

Hanliçe, M. (2011). Şeriye sicillerine göre 19. yüzyıl başlarında Tokat'ta giyim. Selçuk Üniversitesi Türkiyat Araştırmaları Dergisi, (30), 423-456.

Koçu, R. E. (1969). Türk giyim, kuşam ve süslenme sözlüğ̈̈̈. Ankara: Sümerbank Kültür Yay.

Mualla Murat, M. (2002). Zonguldak ve Bartın çevrelerinde halk bilimi (Yüksek lisans tezi). Erişim adresi: https://tez.yok.gov.tr/UlusalTezMerkezi/tezSorguSonucYeni.jsp

Oğuz, G. (2011). 61 numaralı Edirne şer'iye siciline göre 17. yüzyılda Edirneli kadınların giyim kuşam kültürü. Milli Folklor, (92), 107-116.

Özbel, K. (1948). Eski Türk kumaşları, el sanatları-III. Kılavuz Kitapları.

Özkarcı, M. (1995). Eski Türkçe'de kullanılan dokuma ve giyim terimleri. Atatürk Üniversitesi İlahiyat Fakültesi Dergisi, (12), 289-344.

Özlü, Z. (2003). Tereke defterlerine göre 18. yüzyılın II. yarısında Gaziantep'de kadın ve erkek giyiminin karşılaştırılması. Abant İzzet Baysal Üniversitesi Sosyal Bilimler Enstitüsü Dergisi, 2/(7), 105-158.

Yardımcısı, K.G. (2016). Osmanlı dönemi dokuma sanatı ürünlerinden örnekler. International Journal of Cultural and Social Studies. 2/(1), 219-241. 


\section{EKLER}

Ek 1- 1899-1913 yıllarını kapsayan Bartın Şer'iye Sicillerinde Kadın Tereklerinde Yer Alan Giyim Eşyası

\begin{tabular}{|c|c|c|c|}
\hline Sicil numarası & \multicolumn{3}{|c|}{$\begin{array}{l}807 \text { NUMARALI BARTIN ŞER'İYE SİCİİ / } \\
\text { H.1317/1331./M.1899/1913 }\end{array}$} \\
\hline Hüküm numarası & \multicolumn{3}{|c|}{ Sayfa No: 18 Hüküm No: 45} \\
\hline Mahalle /Köy & \multicolumn{3}{|c|}{ Amasra Nahiyesi / Sürmekir Mahallesi } \\
\hline Sahibi & \multicolumn{3}{|c|}{$\begin{array}{l}\text { Kantarcı Oğlu Emin'in, Ahd Karyesi Ahalisinden Seranlı } \\
\text { Oğlu İlyas'ın Kız Kardeşi Fatma Hatuna yaptığı Çeyiz }\end{array}$} \\
\hline & Ürün Türü & Miktarı & Fiyatı \\
\hline & Basma & 24 Arşın & - \\
\hline & Yünlü & 14 Arşın & - \\
\hline & Yünlü & 1 adet & - \\
\hline & Yün Kuşak & 1 adet & - \\
\hline & Telli & 2 arşın & - \\
\hline & Telli Peştemal & 1 adet & - \\
\hline & Peştemal & 1 adet & - \\
\hline & İskarpin Kundura & 1 çift & - \\
\hline & $\begin{array}{l}\text { Sarma İskarpin } \\
\text { Kundura }\end{array}$ & 1 çift & - \\
\hline & Fotin Kundura & 1 çift & - \\
\hline & Abaniye & 1 adet & - \\
\hline & Çubuklu Abaniye & 1 adet & - \\
\hline & Yazma & 2 adet & - \\
\hline & Yazma & 1 adet & - \\
\hline
\end{tabular}


Bartın Tereke Kayıtlarına Göre 19. Yüzyılda Kadınlarda Giyim Kuşam | 219

\begin{tabular}{|c|c|c|c|}
\hline & --------- & 4 arşın & - \\
\hline & Kadife & 2 arşın & - \\
\hline & Çorap & 2 çift & - \\
\hline & Nalın & 1 adet & - \\
\hline & Fes & 1 adet & - \\
\hline & & $\begin{array}{l}\text { Tüm Kiyafet } \\
\text { Tutarı }\end{array}$ & 617,5 Kuruş \\
\hline Sicil numarası & \multicolumn{3}{|c|}{$\begin{array}{l}807 \quad \text { NUMARALI BARTIN } \\
\text { H.1317/1331./M.1899/1913 }\end{array}$} \\
\hline Hüküm numarası & \multicolumn{3}{|c|}{ Sayfa No:21 Hüküm No: 54} \\
\hline Mahalle /Köy & \multicolumn{3}{|c|}{ Şiremir Çavuş Karyesinde } \\
\hline \multirow[t]{8}{*}{ Sahibi } & \multicolumn{3}{|c|}{ Çavuşoğlu Kerimesi Fatma Bint-i Halil } \\
\hline & Ürün Türü & Miktarı & Fiyatı \\
\hline & Telli yelek & 1 adet & 40 kuruş, \\
\hline & Telli entari & 1 adet & 80 kuruş, \\
\hline & Kutni yelek & 1adet & 30 kuruş \\
\hline & Telli peştamal & 1 adet & 40 kuruş \\
\hline & & $\begin{array}{l}\text { Toplam Tereke } \\
\text { Tutarı }\end{array}$ & 6426 Kuruş \\
\hline & & $\begin{array}{l}\text { Kadın Kiyafet } \\
\text { Tutarı }\end{array}$ & 190 Kuruş \\
\hline Sicil numarası & \multicolumn{3}{|c|}{$\begin{array}{lclll}807 & \text { NUMARALI BARTIN ŞER'İYE SİCİL̇ / } \\
\text { H.1317/1331./M.1899/1913 } & & & \\
\end{array}$} \\
\hline Hüküm numarası & \multicolumn{3}{|c|}{ Sayfa No: 61-62 Hüküm No: 149} \\
\hline
\end{tabular}




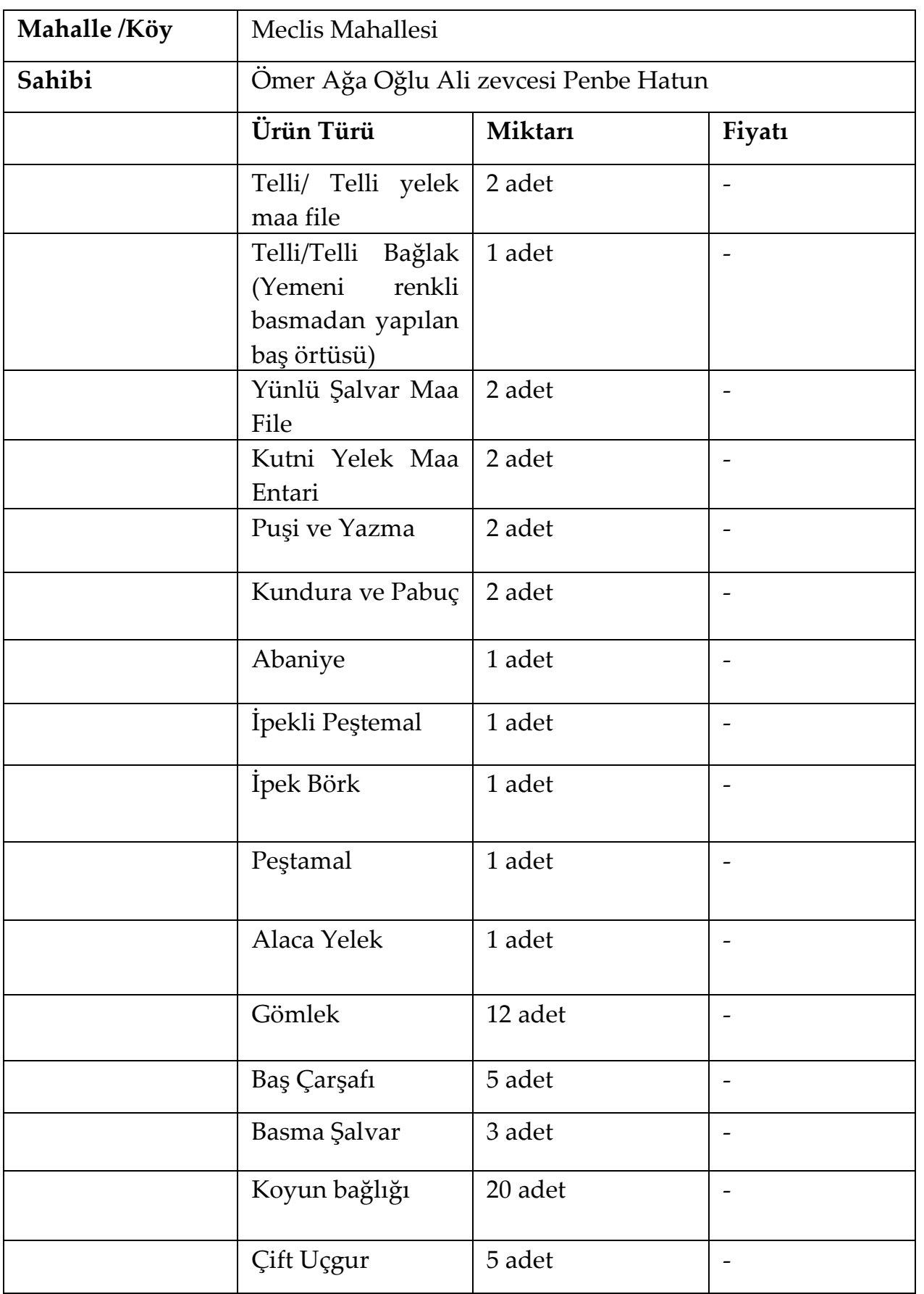


Bartın Tereke Kayıtlarına Göre 19. Yüzyılda Kadınlarda Giyim Kuşam | 221

\begin{tabular}{|c|c|c|c|}
\hline & Allı uçgur & 1 adet & - \\
\hline & Çorap & 1 çift & - \\
\hline & Gümüş Saç bağ & 1 adet & - \\
\hline & $\begin{array}{l}\text { Gümüş Mercanlı } \\
\text { iğne }\end{array}$ & 1 adet & - \\
\hline & $20^{\prime}$ lik takı altını & 20 adet & - \\
\hline & $20^{\prime}$ lik altın & 5 adet & - \\
\hline & $\begin{array}{l}\text { Sandıklı Kulak } \\
\text { Altını }\end{array}$ & 4 adet & - \\
\hline & Altın Kaşlı Yüzük & 2 adet & - \\
\hline & Sandıklı nısf Altın & 5 adet & - \\
\hline & Topaç Altın & 2 adet & - \\
\hline Sicil numarası & \multicolumn{3}{|c|}{$\begin{array}{lllll}807 & \text { NUMARALI BARTIN ŞER'IYY } & \text { SICİLI } & \text { / } \\
\text { H.1317/1331./M.1899/1913 } & & & \\
\end{array}$} \\
\hline Hüküm numarası & \multicolumn{3}{|c|}{ Sayfa 89 Hüküm No: 572} \\
\hline Mahalle /Köy & \multicolumn{3}{|c|}{ Mektep Mahallesinde } \\
\hline Sahibi & \multicolumn{3}{|c|}{$\begin{array}{l}\text { Tirtılzade Halil Efendi Kerimesi ve Meydanlızade Ahmet } \\
\text { Ağa zevcesi Hayriye Hatun }\end{array}$} \\
\hline & Ürün Türü & Miktarı & Fiyatı \\
\hline & Sırmalı baş çarşafı & 13 adet & 130 kuruş, , \\
\hline & Sirmalı havlu & 9 adet & 62 kuruş, \\
\hline & $\begin{array}{l}\text { Telli işleme baş } \\
\text { çarşafı }\end{array}$ & 17 adet & 85 kuruş \\
\hline & $\begin{array}{l}\text { Uskufe yelek ve } \\
\text { kısa entari }\end{array}$ & 2 adet & $\begin{array}{l}201 \text { kuruş } 10 \\
\text { para }\end{array}$ \\
\hline & $\begin{array}{l}\text { Telli yelek ve kısa } \\
\text { entari }\end{array}$ & 2 adet & $\begin{array}{l}112 \text { kuruş } 10 \\
\text { para }\end{array}$ \\
\hline & Kutni Yelek & 1 adet & 80 kuruş \\
\hline & Telli yelek & 1 adet & 120 kuruş \\
\hline
\end{tabular}




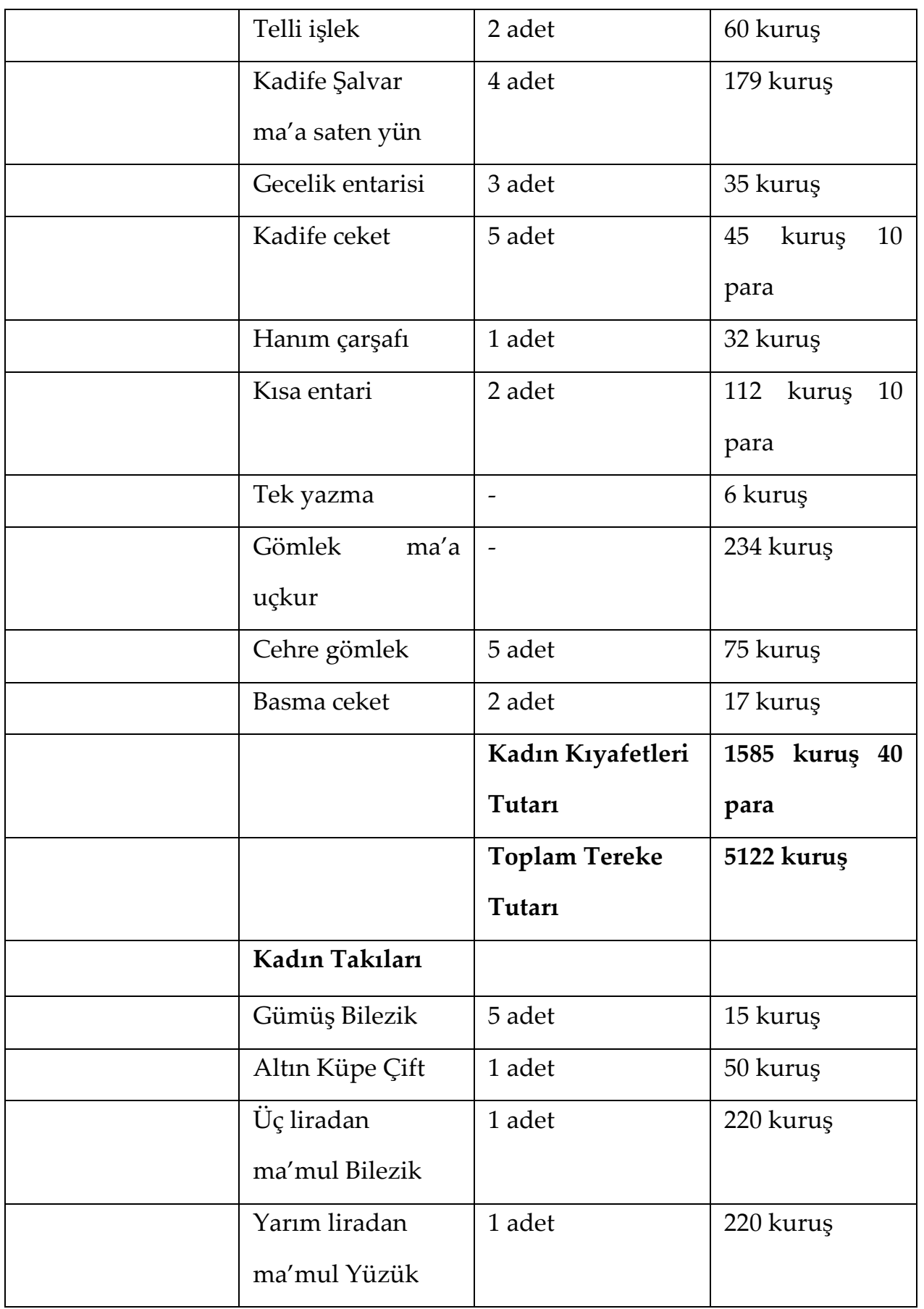


Bartın Tereke Kayıtlarına Göre 19. Yüzyılda Kadınlarda Giyim Kuşam | 223

\begin{tabular}{|l|l|l|l|}
\hline & Elmas Küpe çift & 1 adet & 180 kuruş \\
\hline & & $\begin{array}{l}\text { Kadın Takıları } \\
\text { tutarı }\end{array}$ & $\mathbf{6 8 5}$ kuruş \\
\hline
\end{tabular}

\begin{tabular}{|c|c|c|c|}
\hline $\begin{array}{l}\text { Sicil } \\
\text { numarasi }\end{array}$ & \multicolumn{2}{|c|}{ H.1317/1331./M.1899/1913 } & \\
\hline $\begin{array}{l}\text { Hüküm } \\
\text { numarası }\end{array}$ & \multicolumn{3}{|l|}{ Hüküm No: 68} \\
\hline $\begin{array}{l}\text { Mahalle } \\
\text { /Köy }\end{array}$ & \multicolumn{3}{|c|}{ Bartın Kasabasının Adamescid Mahallesi sâkinelerinden } \\
\hline \multirow[t]{13}{*}{ Sahibi } & \multicolumn{3}{|c|}{$\begin{array}{l}\text { Vefat eden Hacı Kara Hüseyinoğlu Mehmed Efendi zevcesi } \\
\text { Hatice Hâtûn bint-i Daver }\end{array}$} \\
\hline & Ürün Türü & Miktarı & Fiyatı \\
\hline & $\begin{array}{l}\text { Elli bağlık ve elli } \\
\text { uçkur }\end{array}$ & 32 adet & 196 kuruş \\
\hline & Telli baş çarşafı & 16 adet & 88 kuruş \\
\hline & Sırmalı baş çarşafı & 6adet & 96 kuruş \\
\hline & Koyun bağliğ 1 & 10 adet & 50 kuruş \\
\hline & Havlu ve uçgur & 11 adet & 25 kuruş \\
\hline & Bez gömlek & 50 adet & $\begin{array}{l}313 \text { kuruş } 20 \\
\text { para }\end{array}$ \\
\hline & Telli yelek ma'a-kuple & 1 kuruş & 100 kuruş \\
\hline & $\begin{array}{l}\text { Satentilyon şalvar } \\
\text { ma'a-kuple }\end{array}$ & 1 adet & 60 kuruş \\
\hline & Telli yelek ma'a-işlik & 1 adet & 60 kuruş \\
\hline & $\begin{array}{l}\text { Şetâlî yelek } 1 \text { adet } \\
\text { Talasi şalvar } 1 \text { adet }\end{array}$ & & 50 kuruş \\
\hline & $\begin{array}{l}\text { Telli peştamal } 1 \text { adet } \\
\text { Boğça } 1 \text { adet } \\
\text { Abaniye } 1 \text { adet }\end{array}$ & & 100 kuruş \\
\hline
\end{tabular}




\begin{tabular}{|c|c|c|}
\hline Kemer kuşak & 1 adet & 50 kuruş \\
\hline $\begin{array}{l}\text { Pabuç } 1 \text { adet } \\
\text { Corap } 1 \text { adet }\end{array}$ & & 10 kuruş \\
\hline $\begin{array}{l}\text { Canfes şalvar ma'a- } \\
\text { kuple }\end{array}$ & 1 adet & 35 kuruş \\
\hline $\begin{array}{l}\text { Mantin şalvar ma'a- } \\
\text { kuple }\end{array}$ & 1 adet & 50 kuruş \\
\hline $\begin{array}{l}\text { Uskufe yelek } 1 \text { adet } \\
\text { Entari } 1 \text { adet } \\
\text { İşlik } 1 \text { adet }\end{array}$ & & 120 kuruş \\
\hline Telli yelek ma'a-kuple & 1 adet & 70 kuruş \\
\hline Telli şalvar ma‘a-kılap & 1 adet & 65 kuruş \\
\hline $\begin{array}{l}\text { Satentilyon } \\
\text { Şalvar ma'a-kılap }\end{array}$ & 1 adet & 81 kuruş \\
\hline $\begin{array}{l}\text { Altıparmak } \\
\text { (kutni)yelek }\end{array}$ & 2 adet & 150 kuruş \\
\hline Kadife kuple & 1 adet & 15 kuruş 10 para \\
\hline Kadife şalvar & 1 adet & 30 kuruş \\
\hline $\begin{array}{l}\text { Abaniye } \\
\text { peştamal }\end{array}$ & 1 adet & 45 kuruş 20 para \\
\hline $\begin{array}{l}\text { Puşi } 1 \text { adet } \\
\text { Yazma }\end{array}$ & 6 adet & 40 kuruş \\
\hline Kemer kuşak & 1 adet & 32 kuruş \\
\hline Elmaslı çelenk & 1 adet & 300 kuruş \\
\hline & $\begin{array}{l}\text { Kadın Kıyafetleri } \\
\text { Tutarı }\end{array}$ & $\begin{array}{ll}2231 & \text { kuruş } 50 \\
\text { para } & \end{array}$ \\
\hline & $\begin{array}{l}\text { Toplam Tereke } \\
\text { Tutarı }\end{array}$ & $\begin{array}{l}15071 \text { kuruş } 10 \\
\text { para }\end{array}$ \\
\hline Kadın Takıları & & \\
\hline
\end{tabular}


Bartın Tereke Kayıtlarına Göre 19. Yüzyılda Kadınlarda Giyim Kuşam | 225

\begin{tabular}{|c|c|c|c|}
\hline & Mahmudiye Altını & 60 adet & 2400 kuruş \\
\hline & Yirmilik Altın & 50 adet & 1000 kuruş \\
\hline & Altın küpe & 1 çift & 110 kuruş \\
\hline & $\begin{array}{l}\text { Saç Bağında olan } \\
\text { Yirmilik Altın }\end{array}$ & 22 adet & 440 kuruş \\
\hline & & Kadın Takı Tutarı & 3950 kuruş \\
\hline $\begin{array}{l}\text { Sicil } \\
\text { numarasi }\end{array}$ & \multirow{2}{*}{\multicolumn{3}{|c|}{$\begin{array}{l}\text { H.1317/1331./M.1899/1913 } \\
\text { Hüküm No: } 85\end{array}$}} \\
\hline $\begin{array}{l}\text { Hüküm } \\
\text { numarası }\end{array}$ & & & \\
\hline $\begin{array}{l}\text { Mahalle } \\
\text { /Köy }\end{array}$ & \multicolumn{3}{|c|}{$\begin{array}{l}\text { Medîne-i Bartın nevâhîsinden Gölpazarı nâhiyesinin Kızılkum } \\
\text { karyesi }\end{array}$} \\
\hline Sahibi & \multicolumn{3}{|c|}{$\begin{array}{l}\text { Kara Hüseyinoğlu Molla Ramazan zevcesi Hadice Hatun'un } \\
\text { Terekesi }\end{array}$} \\
\hline & Ürün Türü & Miktarı & Fiyatı \\
\hline & Bez topu & 12 adet & 160 kuruş \\
\hline & Nakışlı paça & 6 adet & 15 kuruş \\
\hline & Kafes bedenî & 1 adet & 20 kuruş \\
\hline & Dizlik & 3 adet & 10 kuruş \\
\hline & $\begin{array}{l}\text { Mücedded şetârî } \\
\text { entari }\end{array}$ & 1 adet & 16 kuruş \\
\hline & Şal & 1 adet & 13 kuruş \\
\hline & $\begin{array}{l}\text { Kutni müsta'mel } \\
\text { yelek }\end{array}$ & 1 adet & 20 kuruş \\
\hline & Kulak altunu & 2 adet & 57 kuruş \\
\hline & Gömlek & 3 adet & 16 kuruş \\
\hline
\end{tabular}




\begin{tabular}{|c|c|c|c|}
\hline & Hirka & 1 adet & 12 kuruş \\
\hline & & $\begin{array}{l}\text { Kadın Kıyafet } \\
\text { Tutarı }\end{array}$ & 339 kuruş \\
\hline & & $\begin{array}{l}\text { Toplam Tereke } \\
\text { Tutarı }\end{array}$ & $\begin{array}{lll}841 & \text { kuruş } & 10 \\
\text { para }\end{array}$ \\
\hline $\begin{array}{l}\text { Sicil } \\
\text { numarası }\end{array}$ & \multicolumn{3}{|c|}{$\begin{array}{l}808 \text { NUMARALI BARTIN ŞER'İYE SİCILİ / } \\
\text { H.1317/1331./M.1899/1913 }\end{array}$} \\
\hline $\begin{array}{l}\text { Hüküm } \\
\text { numarası }\end{array}$ & \multicolumn{3}{|c|}{ Hüküm No: 131} \\
\hline $\begin{array}{l}\text { Mahalle } \\
\text { /Köy }\end{array}$ & \multicolumn{3}{|c|}{ Bartın Kasabasının Adamescid Mahallesi } \\
\hline Sahibi & \multicolumn{3}{|c|}{ Hazînedâr-zâde Ömer bin Hüseyin'in zevcesi Huriye } \\
\hline & Ürün Türü & Miktarı & Fiyatı \\
\hline & Koyun yağllı̆ 1 & 25 adet & 125 kuruş \\
\hline & İşlemeli havlu & 6 adet & 30 kuruş \\
\hline & Uçgur & 11 adet & 40 kuruş \\
\hline & Allı yağlık & 2 adet & 20 kuruş \\
\hline & $\begin{array}{l}\text { Telli yelek } \\
\text { ma'a-kılap }\end{array}$ & & 105 kuruş \\
\hline & $\begin{array}{l}\text { Telli yelek ve } \\
\text { kutni kayta } \\
\text { entari }\end{array}$ & 2 adet & 125 kuruş \\
\hline & $\begin{array}{l}\text { Yünlü şalvar } \\
\text { kılap }\end{array}$ & 1 adet & 50 kuruş \\
\hline & $\begin{array}{l}\text { Canfes şalvar } \\
\text { ma'a-kılap }\end{array}$ & 1 adet & \\
\hline & $\begin{array}{l}\text { Telli yelek } \\
\text { ma'a-işlik }\end{array}$ & 2 adet & 40 kuruş \\
\hline
\end{tabular}


Bartın Tereke Kayıtlarına Göre 19. Yüzyılda Kadınlarda Giyim Kuşam

\begin{tabular}{|c|c|c|c|}
\hline & & $\begin{array}{l}\text { Kadın Kıyafetleri } \\
\text { Tutarı }\end{array}$ & 535 kuruş \\
\hline & & $\begin{array}{l}\text { Toplam Tereke } \\
\text { Tutarı }\end{array}$ & $\begin{array}{ll}5422 & \text { kuruş } 36 \\
\text { para } & \end{array}$ \\
\hline $\begin{array}{l}\text { Sicil } \\
\text { numarası }\end{array}$ & \multicolumn{3}{|c|}{$\begin{array}{l}808 \quad \text { NUMARALI BARTIN } \\
\text { H.1317/1331./M.1899/1913 }\end{array}$} \\
\hline $\begin{array}{l}\text { Hüküm } \\
\text { numarası }\end{array}$ & \multicolumn{3}{|l|}{ Hüküm No: 426} \\
\hline $\begin{array}{l}\text { Mahalle } \\
\text { /Köy }\end{array}$ & \multicolumn{3}{|c|}{ Bartın Kasabasının Meclis Mahallesinde sâkine } \\
\hline Sahibi & \multicolumn{3}{|c|}{$\begin{array}{l}\text { Tosunoğlu kerîmesi ve Asmalıoğlu Hüseyin zevcesi Ayşe bint- } \\
\text { i Mustafa }\end{array}$} \\
\hline & Gömlek & 5 adet & 42 kuruş 30 para \\
\hline & Baş çarşafı & 9 adet & 55 kuruş \\
\hline & Gömlek & 2 adet & 9 kuruş 10 para \\
\hline & Uçkur & 6 adet & 11 kuruş 30 para \\
\hline & Koyun bağllğ & 1 adet & 54 kuruş 20 para \\
\hline & Telli işlik & 1 adet & 33 kuruş 30 para \\
\hline & Uskufe yelek & 1 adet & 95 kuruş 10 para \\
\hline & Kadife şalvar ve Ceket & 1 adet & 80 kuruş 20 para \\
\hline & Telli şalvar ceket & 2 adet & 78 kuruş 20 para \\
\hline & Şazen şalvar ceket & 2 adet & 19 kuruş \\
\hline & Yünlü şalvar & 1 adet & 20 kuruş 10 para \\
\hline & Abaniye & 1 adet & 50 kuruş 10 para \\
\hline & $\begin{array}{l}\text { Peştamal } \\
\text { İpek büzgülü kadife } \\
\text { yelek }\end{array}$ & 4 adet & 27 kuruş \\
\hline
\end{tabular}




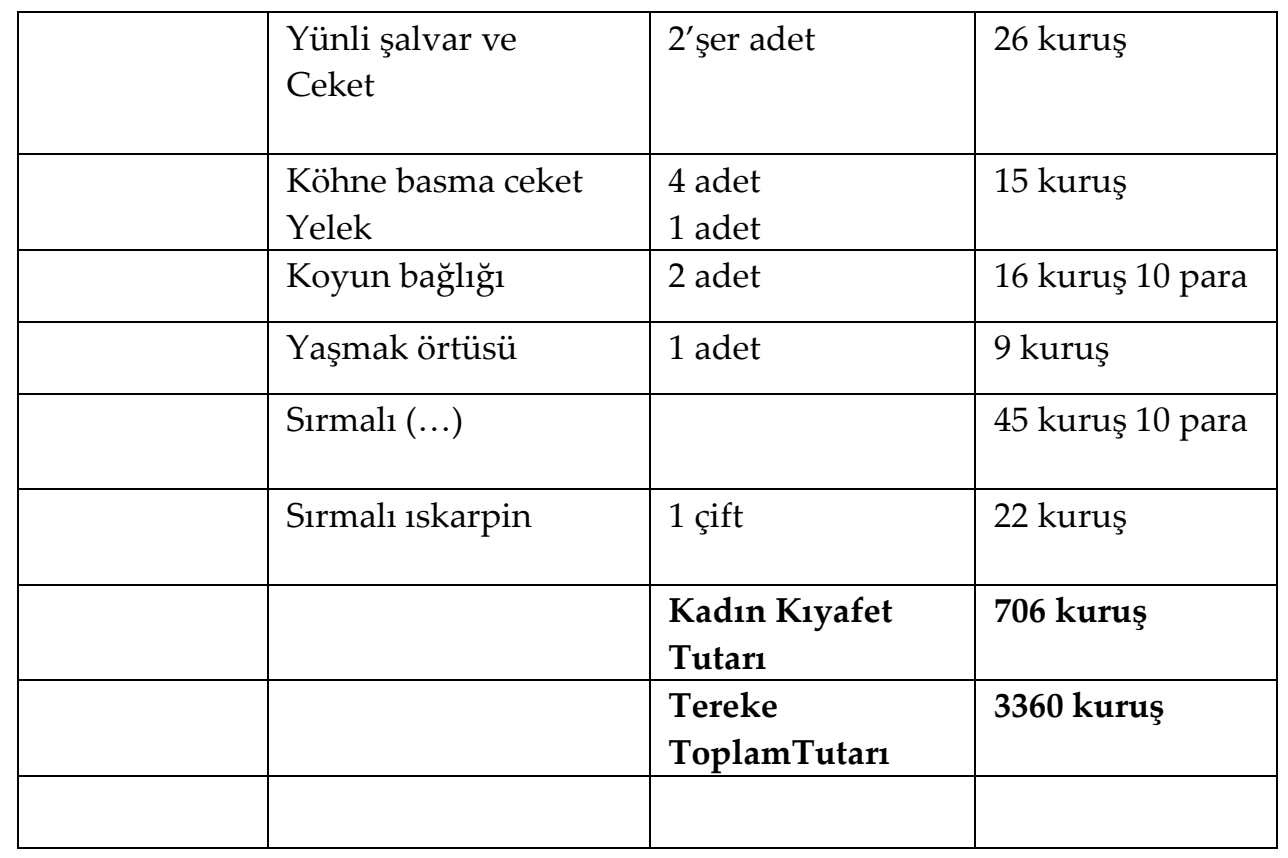

\begin{tabular}{|l|l|l|l|}
\hline Sicil numarası & \multicolumn{4}{|l|}{802 NUMARALI BARTIN ŞER'İY SİCiLİ / H. 1312 } \\
\hline Hüküm numarası & \multicolumn{2}{|l|}{ Sayfa No: 9, Hüküm No: 30 } \\
\hline Mahalle /Köy & \multicolumn{2}{|l|}{ Millet Divanı/ Kıran Karyesi } \\
\hline Sahibi & Halil oğlu kerimesi Hatice bint-i Mahmud zevcesi \\
\hline & Ürün Türü & Miktarı & Fiyatı \\
\hline & Telli yelek & 1 adet & 140 kuruş \\
\hline & Telli kısa entari & 1 adet & 70 kuruş \\
\hline & Kutni yelek & 1 adet & 50 kuruş \\
\hline & Yünlü şalvar kılap & 2 adet & 50 kuruş \\
\hline & Kutni kılap & 1 adet & 30 kuruş \\
\hline & İpekli peştemal & 1 adet & 15 kuruş \\
\hline & & &
\end{tabular}


Bartın Tereke Kayıtlarına Göre 19. Yüzyılda Kadınlarda Giyim Kuşam | 229

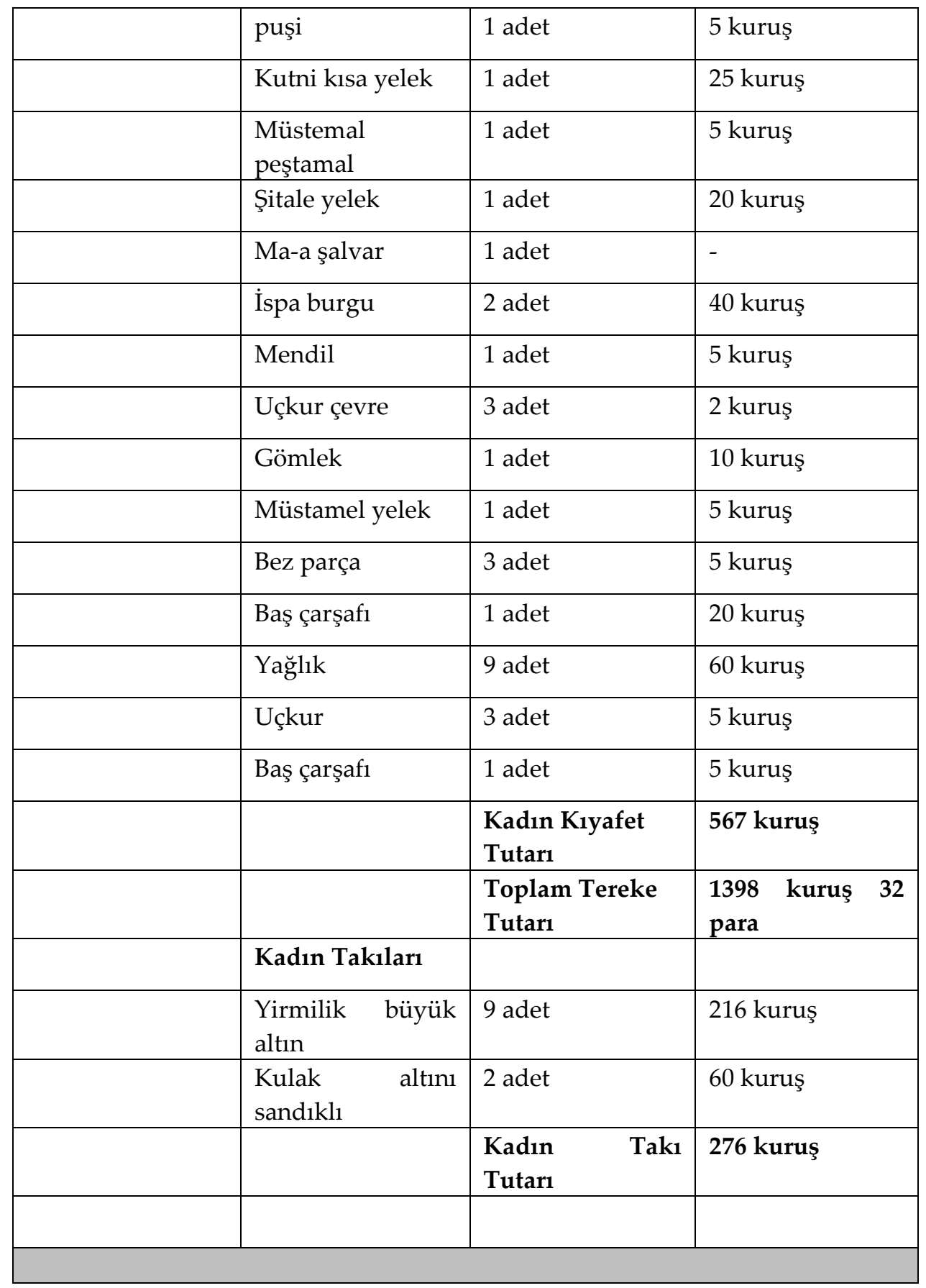


USAD Mine DILLEK

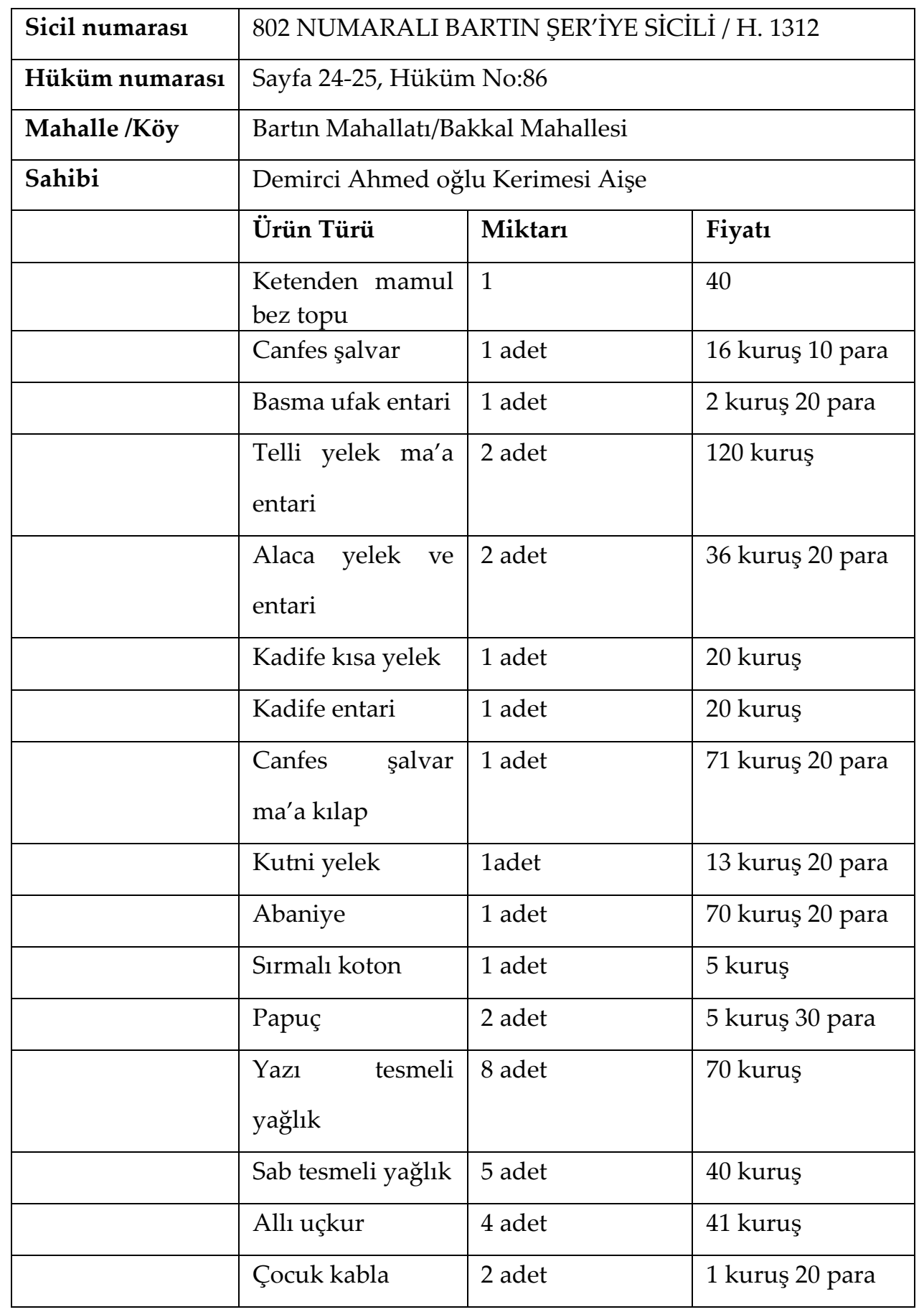


Bartın Tereke Kayıtlarına Göre 19. Yüzyılda Kadınlarda Giyim Kuşam | 231

\begin{tabular}{|c|c|c|c|}
\hline & İşlemeli uçkur & 8 adet & 60 kuruş \\
\hline & cahan sandiğ1 & 1 adet & 24 kuruş 5 para \\
\hline & Gül yağlığı & 26 adet & 70 kuruş \\
\hline & Gömlek & 1 adet & 6 kuruş \\
\hline & Kundura & 1 adet & 7 kuruş \\
\hline & Puşi & 1 adet & 6 kuruş \\
\hline & Yazma & 1 adet & 4 kuruş 20 para \\
\hline & Adi peştamal & 1 adet & 7 kuruş 20 para \\
\hline & Yünlü şalvar & 1 adet & 14 kuruş \\
\hline & Kutni kısa entari & 1 adet & 18 kuruş 10 para \\
\hline & Entari & 1 adet & 5 kuruş \\
\hline & Köhne hirka & 1 adet & 2 kuruş 20 para \\
\hline & Alacadan yelek & 1 adet & 7 kuruş \\
\hline & Hirka & 1 adet & 15 kuruş \\
\hline & & $\begin{array}{l}\text { Kadın Kıyafet } \\
\text { Tutarı }\end{array}$ & $\begin{array}{l}815 \text { kuruş } 235 \\
\text { para }\end{array}$ \\
\hline & & $\begin{array}{l}\text { Toplam Tereke } \\
\text { Tutarı }\end{array}$ & $\begin{array}{l}2172 \text { kuruş } 35 \\
\text { para }\end{array}$ \\
\hline Sicil numarası & \multicolumn{3}{|c|}{802 NUMARALI BARTIN ŞER'İYE SİCİL̇ / } \\
\hline Hüküm numarası & \multicolumn{3}{|c|}{ Sayfa 75, Hüküm No: 275} \\
\hline Mahalle /Köy & \multicolumn{3}{|c|}{ Bartın mahallatı / Cedid Bekir Kalesi } \\
\hline Sahibi & \multicolumn{3}{|c|}{ Ömer Ağa oğlu Mustafa'nın zevcesi Fatıma } \\
\hline & Ürün Türü & Miktarı & Fiyatı \\
\hline & Yünlü hırka & 1 adet & 37 kuruş 20 para \\
\hline
\end{tabular}




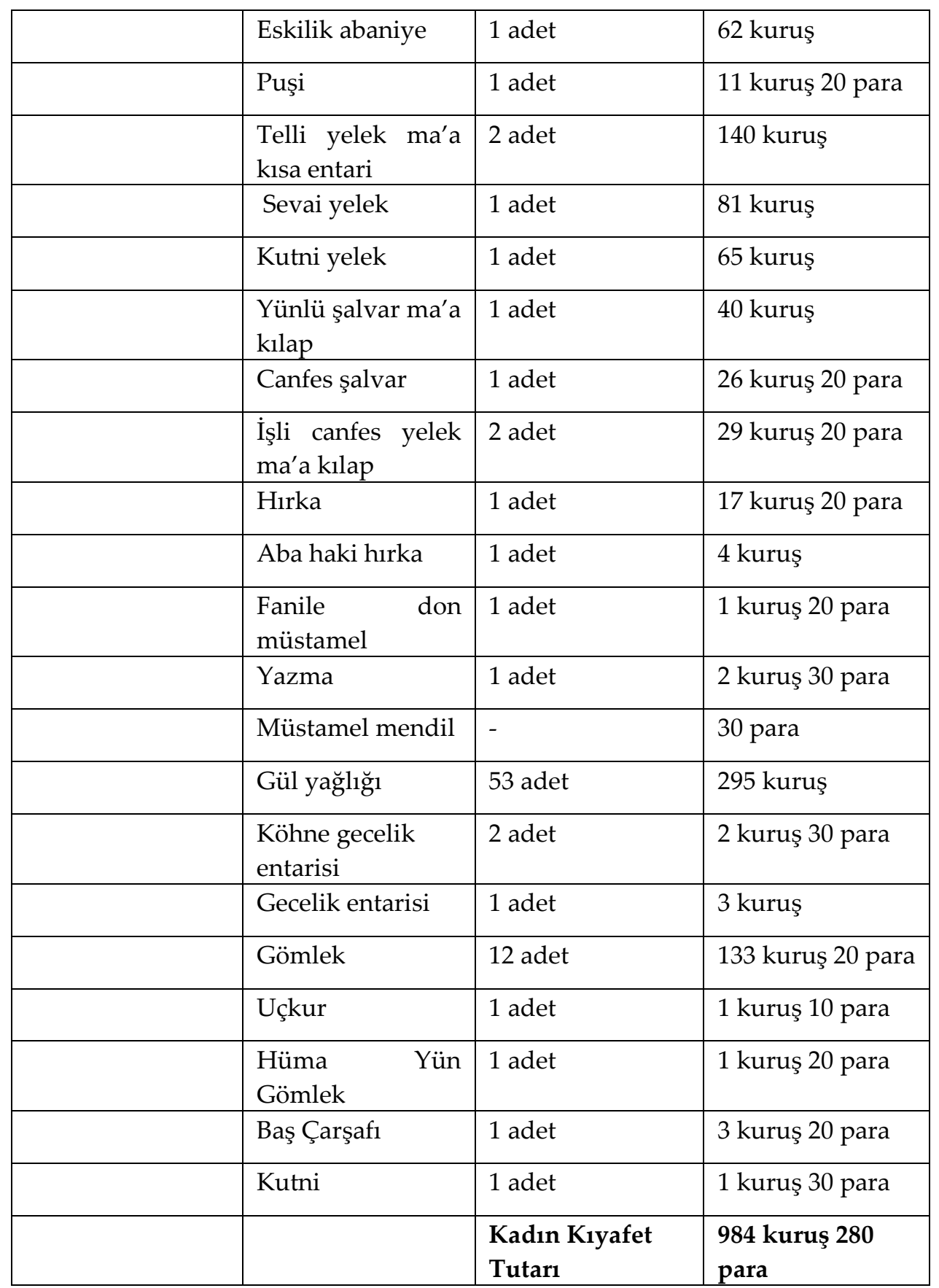




\begin{tabular}{|l|l|l|l|}
\hline & $\begin{array}{l}\text { Tereke Toplam } \\
\text { Tutarı }\end{array}$ & 2712 kuruş \\
\hline \multicolumn{2}{|l}{} \\
\hline
\end{tabular}

\begin{tabular}{|c|c|c|c|}
\hline Sicil numarası & \multicolumn{3}{|c|}{805 NUMARALI BARTIN ŞER'İYE SİCILİ / H. 1314} \\
\hline Hüküm numarası & \multicolumn{3}{|c|}{ Sayfa 65-66 Hüküm No: 121} \\
\hline Mahalle /Köy & \multicolumn{3}{|c|}{ Bolu sancağı dahlinde Bartın mahallatı, Bakkal Mahallesi } \\
\hline Sahibi & \multicolumn{3}{|c|}{ Çınçın oğlu Ahmed (?) } \\
\hline & Ürün Türü & Miktarı & Fiyatı \\
\hline & Abaniye burgu & 1 adet & 40 kuruş 20 para \\
\hline & Ahmediye burgu & 1adet & 10 kuruş \\
\hline & Kutni yelek & 1adet & 60 kuruş \\
\hline & $\begin{array}{l}\text { Telli yelek ma'a } \\
\text { telli kısa entari }\end{array}$ & 2 adet & 81 kuruş \\
\hline & Koyun yağlığı & 10 adet & 25 kuruş \\
\hline & Koyun yağlı̆̆1 & 7 adet & 21 kuruş 20 para \\
\hline & Uçkur & 12 adet & 17 kuruş 20 para \\
\hline & Ağar uçkur & 2 adet & 16 kuruş 20 para \\
\hline & Ağar yağlık & 6 adet & 30 kuruş 10 para \\
\hline & Nene dizlik & 2 adet & 15 kuruş \\
\hline & Gömlek & 1 adet & 5 kuruş \\
\hline & Kutni yelek & 1 adet & 22 kuruş \\
\hline & & Kıyafet Tutarı & $\begin{array}{l}342 \text { kuruş } 90 \\
\text { para }\end{array}$ \\
\hline & & $\begin{array}{l}\text { Toplam Tereke } \\
\text { Tutarı }\end{array}$ & $\begin{array}{l}3580 \text { kuruş } 30 \\
\text { para }\end{array}$ \\
\hline
\end{tabular}


234 | USAD Mine DÍLEK 